BANCA D'ITALIA

E U ROS I S T E M A

Temi di discussione

(Working Papers)

Optimally solving banks' legacy problems

by Anatoli Segura and Javier Suarez

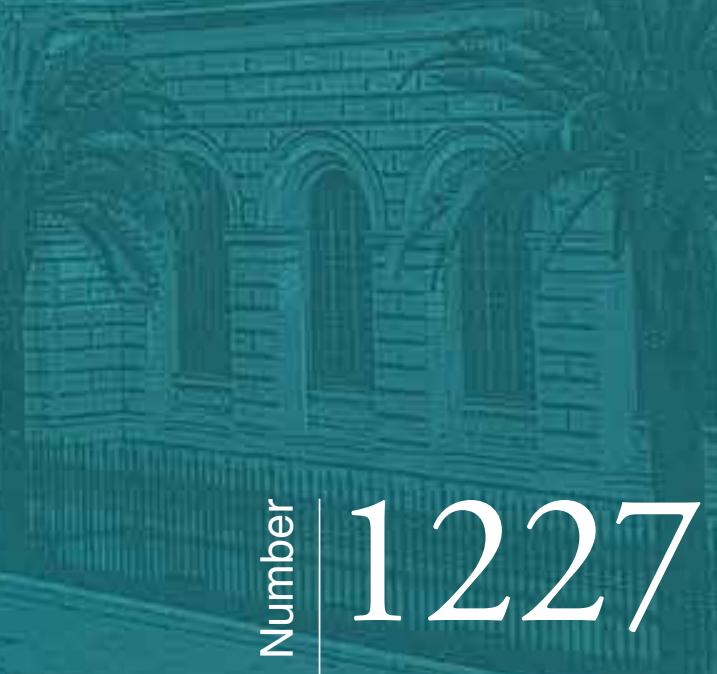



BANCA D'ITALIA

E U R O S I S T E M A

\section{Temi di discussione}

(Working Papers)

Optimally solving banks' legacy problems

by Anatoli Segura and Javier Suarez

Number 1227 - June 2019 
The papers published in the Temi di discussione series describe preliminary results and are made available to the public to encourage discussion and elicit comments.

The views expressed in the articles are those of the authors and do not involve the responsibility of the Bank.

Editorial Board: Federico Cingano, Marianna Riggi, Emanuele Ciani, Nicola Curci, Davide Delle Monache, Francesco Franceschi, Andrea Linarello, Juho Taneli Makinen, Luca Metelli, Valentina Michelangeli, Mario Pietrunti, Lucia Paola Maria Rizzica, Massimiliano Stacchini.

Editorial Assistants: Alessandra Giammarco, Roberto Marano.

ISSN 1594-7939 (print)

ISSN 2281-3950 (online)

Printed by the Printing and Publishing Division of the Bank of Italy 


\title{
OPTIMALLY SOLVING BANKS' LEGACY PROBLEMS
}

\author{
by Anatoli Segura and Javier Suarez ${ }^{*}$
}

\begin{abstract}
We characterize policy interventions directed to minimize the cost to the deposit guarantee scheme and the taxpayers of banks with legacy problems. Non-performing loans (NPLs) with low and risky returns create a debt overhang that induces bank owners to forego profitable lending opportunities. NPL disposal requirements can restore the incentives to undertake new lending but, as they force bank owners to absorb losses, can also make them prefer the bank being resolved. For severe legacy problems, combining NPL disposal requirements with positive transfers is optimal and involves no conflict between minimizing the cost to the authority and maximizing overall surplus.
\end{abstract}

JEL Classification: G01, G21, G28.

Keywords: non performing loans, deposit insurance, debt overhang, optimal intervention, state aid.

\section{Contents}

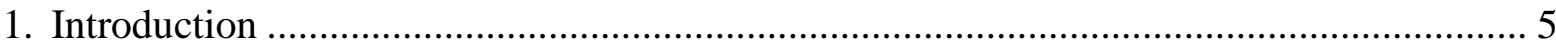

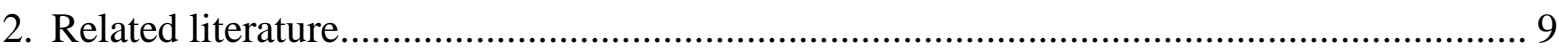

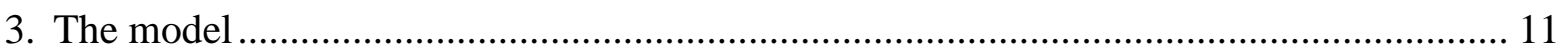

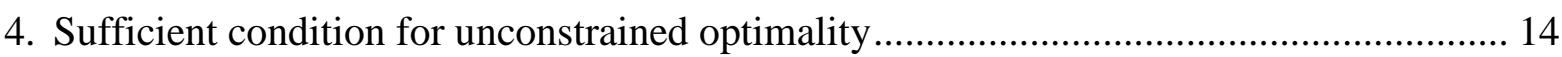

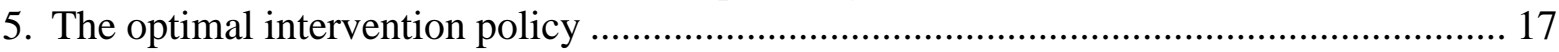

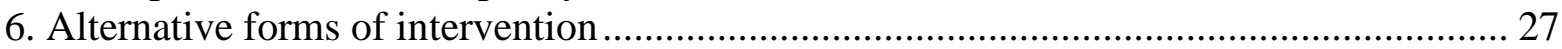

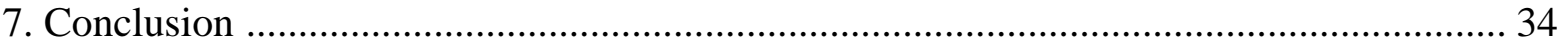

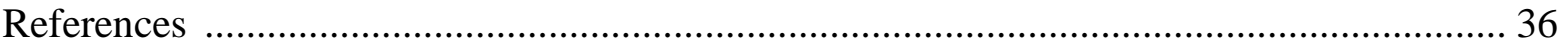

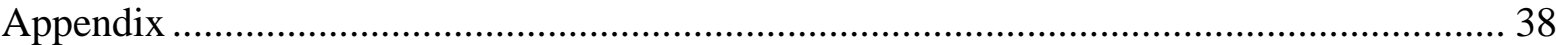

\footnotetext{
'Bank of Italy, Directorate General for Economics, Statistics and Research.

* Center for Monetary and Financial Studies (Cemfi).
} 



\section{Introduction ${ }^{1}$}

The size and persistence of the stocks of non-performing loans (NPLs) held by EU banks in the aftermath of the global financial crisis has worried investors, outside observers, and European authorities in the last years. Weak legacy assets are widely regarded as a source of vulnerabilities and an obstacle to the recovery of bank lending. In July 2017 the Council of the European Union launched an ambitious action plan to address the issue from multiple fronts. ${ }^{2}$ The plan acknowledges the potential role of new instruments such as setting calendars for NPL provisioning, write-off or disposal directly aimed at encouraging or even forcing banks to remove the weak legacy assets from their balance sheets. ${ }^{3}$ However, it is debated whether these measures will be effective in reducing the underlying debt overhang problems, the convenience of combining them with any instance of state aid, and how to address the issue that some of the policies might push a number of banks into resolution.

This paper offers an analytical contribution to the discussion. We develop a stylized model of a regulated bank with a legacy portfolio of NPLs, access to insured deposit funding, and new profitable lending opportunities. We characterize interventions that minimize the joint cost to the deposit guarantee scheme (DGS) and the taxpayers in circumstances where the size of the NPL problem creates a debt overhang problem that prevents new lending. We find that in our setup interventions solely based on NPL disposal requirements and public transfers can achieve unconstrained optimality and involve no conflict between the objective of the authority and the full undertaking of profitable lending opportunities.

At some initial date the bank finances a portfolio of loans with a mixture of insured deposits and owners' capital, in proportions constrained by existing capital regulation. At

\footnotetext{
${ }^{1}$ The views expressed in this paper are our own and do not necessarily coincide with those of the Bank of Italy. We would like to thank Paolo Angelini, Jean Edouard Colliard (discussant), Luc Laeven, Frederic Malherbe, Alberto Martin, Natalya Martynova, Giorgia Piacentino, and Claudia Robles Garcia (discussant), as well as audiences at 10th European Banking Center Network Conference, EuroFIT Conference at UCL, Bank of Italy, ECB, Bundesbank, and Cass Business School for helpful comments. Contact e-mails: anatoli.seguravelez@bancaditalia.it and suarez@cemfi.es.

${ }^{2}$ The plan foresees policies on several fronts, from reforms directed to improving the efficiency of insolvency procedures or allowing the establishment of active secondary markets for NPLs, to introducing supervisory guidance on banks' management of NPLs (see Council of the European Union, 2017). Prior initiatives by European authorities to diagnose and address the problem include those of the European Banking Authority (2016), the European Central Bank (2017), and the European Systemic Risk Board (2017).

${ }^{3}$ In the US those requirements and incentives have existed for longer, e.g. in the form of accounting rules that imply the full write-off of bad loans within a limited time horizon and a tax treatment whereby the losses associated with defaulted exposures become only tax deductible at the time the exposure is written-off.
} 
an interim date, which is the focus of the analysis, a fraction of the initial loans become non-performing, meaning that their payoffs in all future states of the economy will be lower than those of the performing loans. Due to provisioning and capital requirements applied on them, NPLs may require bank owners to recapitalize the bank at the interim date. Yet, if the bank's capital is insufficient to absorb the losses implied by the NPLs in some future states, a bank that retains a large amount of NPLs may end up failing, imposing a cost to the DGS.

The possibility that NPLs can lead the bank to fail affects bank owners' decisions in two interrelated manners. First, it makes them reluctant to undertake new good lending. Part of such lending may need to be funded with new capital provided by them, who anticipate that part of the returns will effectively go to the DGS in the form of lower losses in case of failure (or a lower probability of bank failure). So bank owners face a situation akin to the classical debt overhang problem of Myers (1977) and may pass up profitable lending opportunities. Second, bank owners may also be reluctant to provide even just the new capital necessary to comply with capital regulation after recognizing the losses implied by the NPLs, since such capital injection reduces the losses otherwise covered by the DGS if the bank fails. So bank owners may prefer not to comply with the regulatory requirements, driving the bank into resolution. ${ }^{4}$

In this context, we consider the problem faced by an authority whose objective is to minimize the cost of the guarantees offered by the DGS and any (other) transfer from taxpayers implied by the intervention. ${ }^{5}$ We focus on an authority whose available policies consist of mandatory NPL sales and monetary transfers to the bank, and later show that this intervention toolkit is sufficient to achieve optimal policies. The first policy tool can be regarded equivalent to setting a calendar for the bank to dispose of some of its NPLs. The second tool could be reinterpreted as a scheme subsidizing such NPL disposal, e.g. by

\footnotetext{
${ }^{4}$ We use "resolution" to refer to any form of orderly liquidation of a bank that does not comply with capital regulation or any other requirement set by the authorities. To keep things simple, we assume that resolution implies no other inefficiency than the loss of the bank's new lending opportunities. Since even under this assumption bank resolution is never an outcome of the optimal intervention policies considered below, the existence of additional inefficiencies would have no effect on our results.

${ }^{5}$ In practice, most DGSs get funded in normal times with fees paid by the insured banks but such funding is insufficient in crisis times, thus requiring a fiscal backstop. We simplify the discussion by not explicitly referring to the funding of the DGS but assuming, instead, that the authority dealing with the bank aims to minimize the joint costs of the NPL problem to the DGS and the taxpayers.
} 
means of a publicly sponsored asset management company (AMC). Once the authority sets its policy, bank owners decide whether to be compliant or to precipitate the resolution of the bank.

We first provide a sufficient optimality condition for a more general class of interventions that might involve not only NPL disposal requirements and public transfers, but also capital requirements on each loan type and mandatory new lending decisions. The condition states that an intervention policy is unconstrained optimal if it meets two criteria. First, it either has no cost to the authority or leaves zero rents to the bank owners. Second, it avoids resolution and induces the full undertaking of the new lending opportunities. These criteria build on the intuition that, given that insured depositors are always entirely repaid, a reduction of the cost to the authority can only be achieved through the undertaking of profitable new lending and/or a reduction in bank owners' rents. Interestingly, optimal policies avoid resolution, even when the cost of the NPL problem to the authority is positive because resolving the bank would only increase the cost in the amount of the net present value (NPV) of the bank's new lending opportunities. ${ }^{6}$

We then show that there are combinations of NPL disposal requirements and transfers that allow to meet the unconstrained optimality criteria. First, after disposing of a sufficiently large fraction of their NPLs, the bank owners of a compliant bank are always willing to lend. The reason is that the NPL disposal reduces the DGS subsidy whose loss would otherwise make bank owners reluctant to undertake the new lending. Second, if the disposal of the NPLs is so onerous to the bank owners that they would prefer to let the bank being resolved, the authority can make a positive monetary transfer just big enough to induce compliance (and new lending). ${ }^{7}$ A "stick and carrot" policy that combines NPL disposals with public transfers (that leave zero rents to the bank owners) is thus optimal. Besides, removing the debt overhang problem in a bank with more NPLs requires the bank to dispose of a larger fraction of them and may have to be accompanied with larger public transfers to avoid resolution.

\footnotetext{
${ }^{6}$ In a situation in which banks with NPLs only have risky lending opportunities with negative NPV, bank owners might be tempted undertake them to increase their gambling against the DGS. In these circumstances, we would have analogously that an intervention policy is optimal if either it has no cost to the authority or it leads to the resolution of the bank. In addition, under any optimal intervention new lending would not be undertaken.

${ }^{7}$ We identify cases in which NPL disposal is not necessary to prevent the debt overhang problem but still the authority needs to make positive transfers to prevent bank owners from letting the bank being resolved.
} 
We complement the analysis by discussing a number of variations in the policy toolkit that, in addition to their practical relevance, help us test the robustness of our key results. First, we consider interventions based on a purchase and assumption (P\&A) transaction in which, following the disposal of some of the NPLs of the distressed bank, its remaining assets (including new lending opportunities) and its liabilities are transferred to a healthier bank. We show that the financial strength of the healthier bank reduces the incentives of the merged bank (relative to the stand-alone distressed bank) to undertake new lending and thus the need for NPL disposals relative to the baseline stand-alone optimal intervention. This might help rationalize the historical preference of the FDIC and other resolution authorities for this type of interventions. Yet, inducing the voluntary participation of the healthier bank involves the same minimum amount of public transfers and minimum overall cost to the authority as the stand-alone interventions of the baseline setup.

Second, we show that introducing prudential adjustments to the accounting provisions on NPLs can reduce the potential losses caused by the NPLs to the DGS and, thereby, diminish bank owners' reluctance to undertake profitable new lending in essentially the same manner as NPL disposal requirements do. However, prudential provisioning does not alter the need or not for public transfers relative to the baseline optimal interventions. So prudential provisioning and NPL disposal requirements are just perfect substitutes in our setup.

In a third extension, we analyze the case in which the bank is also initially funded with uninsured long-term debt on which the authority may exercise some bail-in power as part of its intervention policy. We show that, when the bank has sufficiently many NPLs, the exercise of such bail-in power is essential to preserve the optimality to the authority of inducing the new lending since, otherwise, it would imply an onerous transfer of value from the authority to the long-term debtholders.

Finally, we consider an authority that is not allowed to make transfers to the bank, and find that there are cases in which such authority will push the bank into resolution by imposing a sufficiently large NPL disposal requirement. The reason is that, in these cases, it is impossible to induce new lending and keeping the bank unresolved would simply increase the liabilities of the DGS. ${ }^{8}$ Relative to the optimal unconstrained policy, the expected cost to the

\footnotetext{
${ }^{8}$ As first noted by Merton (1974), the DGS liabilities are akin to having granted a put option on the bank assets to the insured depositors. Thus the residual riskiness of the NPLs increases the expected cost of the liability relative to the situation in which the position is closed at the interim date by selling the NPLs at
} 
authority in these cases increases by exactly the NPV of the forgone lending opportunities. Eventually, having restrictions on state aid in this setup would backfire and have a cost to the DGS in excess of the money saved by prohibiting the transfer associated with the optimal unconstrained intervention.

The paper is organized as follows. Section 2 describes the related literature. Section 3 presents the model. In Section 4 we establish conditions for the optimality of a public intervention policy in our setup. Section 5 shows that interventions based on NPL disposal requirements and public transfers can attain optimality and characterizes the minimal optimal intervention policy of this class. Section 6 considers the possibility of attaining optimality with a different toolkit and in the presence of uninsured long-term debt. Section 7 concludes. Appendix A includes the proofs of the formal results in the paper, Appendix B contains details on variations of the baseline model, and Appendix $\mathrm{C}$ discusses the baseline results for a parameter configuration not covered in the main text.

\section{Related literature}

In our setup, the shareholders of the regulated bank face a reluctance to reduce leverage and a debt overhang problem similar to those described in classical corporate finance references. Black and Scholes (1973) and Merton (1974) were first to establish the conflict of interest whereby shareholders might be reluctant to leverage reductions in order to preserve the value of their default option. As confirmed by Admati et al. (2018), the conflict will generally push shareholders to increase leverage over time and, if the firm is required to reduce its leverage, shareholders will prefer doing it by selling the firm's safer assets rather than by raising new equity.

The underinvestment problem caused by the appropriation of the returns of new investment by a firm's more senior creditors (debt overhang) was first described by Myers (1977). We analyze a similar problem in the special policy-relevant context in which a bank can be funded with insured deposits provided it complies with capital regulation and other requirements set by a bank authority. And we address the problem from the perspective of an authority which cares about the costs to the DGS and the taxpayers.

In an institutional set-up similar to ours, Bahaj and Malherbe (2017) show the ambiguous

their fair price. 
impact of rising capital requirements on the lending incentives of banks with legacy loans. The reason is that forcing the injection of new capital mitigates the debt overhang problem but also reduces the risk-shifting motives for undertaking new lending. The paper focuses on the implications for lending, and does not address the design of optimal interventions.

Our paper is also related to papers aimed at characterizing optimal bank interventions in the presence of asymmetric information and gambling opportunities. Bruche and Llobet (2013) address the problem of preventing the inefficient rolling-over of bad loans by a distressed bank from a mechanism design perspective and with the objective of maximizing the overall social surplus. The paper characterizes the optimal intervention scheme in the presence of asymmetric information on the amount of bad loans held by the bank, which includes quantity-dependent subsidies to the disposal of bad loans disposal while leaving no informational rents to the bank owners. ${ }^{9}$

In Philippon and Schnabl (2013) asymmetric information on the quality of banks' new investment opportunities gives rise to both underinvestment in profitable projects and opportunistic investment in unprofitable risky ones. The welfare maximizing policy consists of cash injections (that limit the debt overhang) in exchange for preferred stock and warrants (that limit risk shifting temptations).

Diamond and Rajan (2011) show the role of mandatory illiquid asset disposals in a context where the interaction between distressed banks (that hold illiquid assets for gambling reasons) and sound banks (that hoard liquidity in order to profit from potential future fire sales by distressed banks) produces suboptimal investment in good assets.

In our paper, the new profitable lending opportunities belong to the same banks that hold the damaged assets which, in turn, are regulated commercial banks with access to insured deposit funding, as most of the banks affected by a high NPL ratio in Europe. As in some of the referred papers, we consider interventions forcing the sale of the damaged legacy assets but the interventions in our setup are directed to minimize the cost of the NPL problem to the authority rather than some broader measure of social surplus.

Finally, our paper is related to the literature on the motivations and implications of bank bailouts (including Freixas, 1999; Acharya and Yorulmazer, 2007; Diamond and Rajan, 2012;

\footnotetext{
${ }^{9}$ Related asymmetric information setups in which banks fail to efficiently restructure their (unobservable) bad loans due to their gambling incentives can be found in Berglöf and Roland (1995), Aghion et al. (1999), and Mitchell (2001).
} 
Farhi and Tirole, 2012; and Keister, 2016). Most of this literature considers the conflict between the ex-post optimality of bail-outs in the presence of bank default externalities and their negative ex-ante incentive effects (moral hazard). In our model, given the presence of deposit insurance, the positive transfers involved in some of the optimal interventions do not leave rents to bank shareholders and, thus, do not aggravate the ex ante moral hazard problem already generated by the presence of deposit insurance. ${ }^{10}$

\section{The model}

Consider a model with three dates, $t=0,1,2$, a bank, and three classes of agents with a stake at the bank: bank owners, depositors, and an authority. All the agents are risk neutral and have deep pockets and a zero discount rate. Bank owners provide equity funding to the bank and decide the bank's funding and investment policy subject to capital regulation and the intervention policy set by the authority. Depositors provide financing to the bank in the form of deposits fully insured by a DGS. ${ }^{11}$ The authority runs the DGS, fixes some intervention policy at the interim date $(t=1)$, and resolves the bank, if necessary.

The bank's initial balance sheet At $t=0$ the bank originates a measure one of ex ante identical loans that pay off at $t=2$. The bank is initially funded with a mix of equity provided by its owners, $e_{0}$, and insured deposits, $d_{0}$. Regulation establishes a minimum capital requirement at both $t=0$ and $t=1$. At $t=0$, the capital requirement per unit of lending is $\gamma>0$, and we assume it to be binding, that is, $e_{0}=\gamma$ and $d_{0}=1-\gamma \cdot{ }^{12}$ The focus of our analysis is on the sequence of events following the recognition at $t=1$ that some of the initial loans become non performing.

The loan portfolio at the interim date At $t=1$ a fraction $x$ of the bank loans deteriorate. We refer to these loans as NPLs, as opposed to the rest, called performing loans. The type of each loan is public information. The payoffs of a performing loan at $t=2$ are denoted $B_{s}$, where $s$ is the state of the economy at that date, which can be

\footnotetext{
${ }^{10}$ See Appendix B.1, where we endogenize some ex ante monitoring decision by the bank.

${ }^{11}$ We will treat bank owners and depositors as a single representative agent of each class, even if still referring to them in plural.

${ }^{12}$ In Appendix B.1 we also endogenize bank owners' capital structure decision at $t=0$ and show the optimality of these choices.
} 
high $(s=H)$ or low $(s=L)$, with probabilities $\mu$ and $1-\mu$, respectively. Similarly, the payoffs of an NPL in each final state $s$ are denoted $Q_{s}$. The capital requirement per unit of principal still equals $\gamma$ for performing loans but becomes $\phi>\gamma$ for NPLs, reflecting the combined impact of provisioning standards and regulatory capital requirements. We make the following assumption:

Assumption $1 Q_{L}<1-\phi<Q_{H}<1-\gamma<B_{L}<B_{H}$.

The assumption fixes the relationship between loan returns and between them and capital requirements. First, the return of each type of loan is higher in state $H$ than in state $L$. Second, the capital required on performing loans is enough to fully cover their potential losses in state $L\left(\gamma>1-B_{L}\right)$. Third, the interim capital requirement on NPLs is not sufficient to fully absorb the losses realized on these loans in state $L\left(\phi<1-Q_{L}\right)$. Fourth, the interim capital requirement on NPLs is sufficient to fully absorb their losses in state $H\left(\phi>1-Q_{H}\right)$, but the initial capital requirement is not $\left(\gamma<1-Q_{H}\right)$. The first three properties are essential in order for the presence of NPLs to create a potential debt overhang problem vis-à-vis new lending (described next). The fourth property is only imposed for simplicity. ${ }^{13}$

New lending opportunities At $t=1$ the bank has the opportunity to originate an additional measure $y$ of ex ante identical loans with the same capital requirement at $t=1$ and payoff structure at $t=2$ as the existing performing loans. Moreover, we assume that:

Assumption $2 \quad E\left[B_{s}\right]>1$.

The assumption states that the expected payoff of performing and new loans is larger than one, which in particular implies that new loans have positive NPV.

Public intervention policies Due to the presence of NPLs, the DGS may face disbursements associated with either the insolvency of the bank at $t=2$ or its resolution at $t=1$ (in case its owners are not willing to provide the capital necessary to keep it compliant with regulatory requirements at that date). The authority is assumed to adopt an intervention

\footnotetext{
${ }^{13}$ Specifically, all the results in the paper would hold if the assumption $1-\phi<Q_{H}<1-\gamma$ were replaced with the weaker assumption $E\left[Q_{s}\right]<1-\gamma$.
} 
policy at $t=1$ directed to minimize the overall expected cost of the DGS liabilities and any (other) public funds involved in dealing with the bank. To focus the discussion, we assume for the time being that the authority can ask the bank to dispose of a fraction $\alpha \in[0,1]$ of its NPLs and make a transfer $T \geq 0$ to the bank conditional on bank owners executing the disposal and injecting the capital needed to comply with capital regulation after the intervention. We will later show that the focus on this toolkit implies no loss of generality in the sense that the access to any other tools would not allow to reduce the overall expected cost of the legacy problem to the authority

We assume that the NPLs can be disposed of at $t=1$ by selling them at a market price equal to their fundamental value, $q=E\left[Q_{s}\right]$.

The bank's response After observing the intervention policy $(\alpha, T)$, the bank decides at $t=1$ whether to comply with it (and the existing capital requirements) or not. If compliant, the bank decides how much new lending $I \in[0, y]$ to undertake and some funding decisions $\left(\Delta e, d_{1}\right)$ compatible with capital requirements, where $\Delta e$ is the net contribution made by bank owners at $t=1$ (equity injections, if positive, or dividend payments, if negative) and $d_{1}$ are the deposits of the bank at $t=1$, which may differ from $d_{0}$.

Resolution A bank not compliant with the intervention (and the existing capital requirements) is resolved. Resolution means that the bank owners obtain a zero payoff and the bank loses its new lending opportunities. The DGS appropriates the existing performing and non-performing loans of the bank, sells them at their fundamental price, and uses the proceeds to fully or partially pay back the deposits. Hence, if the residual net worth of the bank is negative, the DGS makes a loss, while if it is positive, the DGS makes a profit. ${ }^{14}$ Thus, in this setup, the only surplus loss associated with bank resolution is the NPV of the new lending opportunities.

Equilibrium at $t=1$ The authority and the bank owners play a sequential game at $t=1$ in which the authority moves first. An equilibrium consists of an intervention policy $\left(\alpha^{*}, T^{*}\right)$ by the authority and a decision by bank owners on whether to be compliant and, in that

\footnotetext{
${ }^{14}$ We could equivalently assume that any positive residual net worth is distributed to the bank owners. It is in fact possible to prove that in either case bank owners take decisions that avoid resolution whenever the residual net worth under resolution is non-negative.
} 
case, the amount of new lending $I^{*}$ and some funding decisions $\left(\Delta e^{*}, d_{1}^{*}\right)$ compatible with capital requirements, such that:

1. The authority minimizes the overall expected cost of the NPL problem to the DGS and the taxpayers.

2. Bank owners maximize the NPV of their wealth.

\section{Sufficient condition for unconstrained optimality}

In this section we establish a sufficient condition for the optimality to the authority of what we call unconstrained interventions: interventions of a broader class than the $(\alpha, T)$ interventions that she deploys in the baseline setup. We will later show that there are interventions of the simpler $(\alpha, T)$ class that satisfy such condition and hence allow the authority to reach unconstrained optimality.

Unconstrained intervention policies allow the authority to set at $t=1$ not only an NPL disposal requirement $\alpha$ and a public transfer $T$ but also the size of the new lending undertaken by the bank $I \in[0, y]$, and its new capital structure as characterized by its owners' net capital injection $\Delta e$ and the new deposit amount $d_{1} \cdot{ }^{15}$ An unconstrained intervention policy is thus described by a tuple $\left(\alpha, T, I, \Delta e, d_{1}\right)$. The authority's choices must satisfy the bank's sources and uses of funds equality, which says

$$
q \alpha x+T+\Delta e+\left(d_{1}-d_{0}\right)=I .
$$

The left hand side (LHS) of this equation includes the bank resources from the sale at price $q$ of a fraction $\alpha$ of its NPLs, the public transfer $T$, the net equity injection by bank owners, and the variation in bank deposits between $t=0$ and $t=1$ (where the last two can be negative). The right hand side (RHS) accounts for the use of those funds in undertaking the new lending $I$.

As in the baseline setup, bank owners have the option not to comply with the intervention policy set by the authority, in which case the bank is resolved, bank owners obtain a zero payoff, and no new lending takes place.

\footnotetext{
${ }^{15}$ In this design, we allow the authority to override the minimum capital requirements that, in contrast, must be satisfied by the bank under the simpler class of interventions.
} 
For a given intervention $\left(\alpha, T, I, \Delta e, d_{1}\right)$, the total continuation value of the assets of a compliant bank at $t=1$ is given by:

$$
V=E\left[Q_{s}\right](1-\alpha) x+E\left[B_{s}\right](1-x+I)
$$

which takes into account that the bank ends $t=1$ with NPLs and performing loans amounting to $(1-\alpha) x$ and $1-x+I$, respectively. This total continuation value can be decomposed as

$$
V=E+D-G
$$

where $E$ is the continuation value of bank owners' equity stake, $D=d_{1}$ is the continuation (and face) value of the insured deposits, and $G$ is the expected cost of the guarantees offered by the DGS on those deposits. The variables in (3) are generally functions of $x, \alpha, I$, and $d_{1}$, but we will omit these arguments when there is no risk of confusion. ${ }^{16}$

The present value of the compliant bank to its owners at $t=1$ minus the net equity injection $\Delta e$ is then given by

$$
\Pi=-\Delta e+E
$$

Analogously, the expected cost of the NPL problem to the authority is

$$
C=G+T
$$

Notice that $\Pi$ and $C$ are the objective functions that, conditional on bank compliance, bank owners and the authority will aim to maximize and minimize, respectively, at $t=1$.

Using the sources and uses of funds equality in (1), the total continuation value of bank assets in (2) and its decomposition in (3), we have

$$
\begin{aligned}
\Pi-C & =-\Delta e+E-T-G \\
& =V-D-\left(I-q \alpha x-\left(d_{1}-d_{0}\right)\right) \\
& =\left(E\left[Q_{s}\right] x+E\left[B_{s}\right](1-x)-d_{0}\right)+\left(E\left[B_{s}\right]-1\right) I
\end{aligned}
$$

which uses the definitions of $\Pi$ in (4) and $C$ in (5). This equation says that the difference between the net value of the bank to its owners and the cost of the bank to the authority

\footnotetext{
${ }^{16}$ The transfer $T$ and the net equity injection $\Delta e$ affect the resources available for the bank to undertake its lending at $t=1$ as captured by (1) but have no direct effect on the overall continuation value of the bank and its components as expressed in (3).
} 
equals the sum of the net overall value of the bank at the beginning of $t=1$ (understood as the value of its initial loans net of the initial obligations vis-à-vis the depositors) and the NPV of the lending undertaken at $t=1$.

Importantly, the only element of $\left(\alpha, T, I, \Delta e, d_{1}\right)$ that affects $\Pi-C$ is the amount of new lending $I$. So the intervention policy $(\alpha, T)$ decided by the authority has no effect on $\Pi-C$ other than through the induced choice of $I$, which also means that for a fixed $I$, the intervention policy affects the distribution of the total continuation value of bank assets between bank owners $(\Pi)$ and the authority $(C)$, but not such total continuation value.

From (6), the cost of the bank to the authority, conditional on the bank being subsequently compliant, can be expressed as

$$
C=\Pi-\left(E\left[B_{s}\right]-1\right) I-\left(E\left[Q_{s}\right] x+E\left[B_{s}\right](1-x)-d_{0}\right)
$$

The equation implies, on the one hand, that an increase in $\Pi$ leads (other things equal) to an increase in $C$. The reason is that, for given values of the bank's assets and initial deposits, a higher value to the bank owners can only come from an increase in the subsidies $G$ associated with the guarantees provided by the DGS. On the other hand, an increase in the profitable lending undertaken by the bank at $t=1$ leads (other things, including $\Pi$, equal) to a reduction in the cost of the bank to the authority, which would benefit from the positive NPV of the new lending.

The expression for $C$ in (7) has been derived assuming the bank is compliant with the intervention at $t=1$, but is is easy to check that it also holds in case of non-compliance and resolution, when $\Pi=I=0$.

So, in general, in order to minimize the $\operatorname{cost} C$, the authority should aim to simultaneously (i) minimize the net value of the bank to its owners, $\Pi$, and (ii) maximize the undertaking of the new lending opportunities, $I$. The following result builds on this intuition to establish a sufficient condition for the optimality of public interventions on NPLs:

Lemma 1 (Sufficient condition for unconstrained optimality) Let $\left(\alpha, T, I, \Delta e, d_{1}\right)$ be an intervention policy that:

C1. Leads to a zero cost of the NPL problem to the authority $(C=0)$ or to zero net value of the bank to its owners $(\Pi=0)$. 
C2. Induces the bank to be compliant and to undertake all its new lending $(I=y)$.

Then $\left(\alpha, T, I, \Delta e, d_{1}\right)$ is an optimal intervention policy.

The intuition for the sufficient condition for optimality set in this lemma is as follows. Obviously, if a policy has zero cost to the DGS and the taxpayers then it is optimal. Consider the alternative case in which the policy has a positive $\operatorname{cost} C$. From (7), we obtain that the only way to reduce $C$ is to reduce bank owners' net value $\Pi$ or to increase new lending $I$. But, if the policy already leads to $\Pi=0$ and maximum new lending, $I=y$, then there is no room for reducing $C$ any further. In fact, an additional reduction in the net value of the bank to its owners would lead them to opt for non-compliance (resolution), in which case the new lending would not be at all undertaken and, again from (7), the cost of the NPL problem to the authority would increase.

Let us highlight in particular that the resolution policies satisfying the sufficient condition for optimality avoid pushing the bank owners into resolution, even when the overall cost of the NPL problem to the DGS and the taxpayers is positive. Resolving the bank would increase $C$ because it would preclude the authority from using the NPV of the bank's new lending opportunities in order to reduce the expected value of the liabilities of the DGS.

Recall that in the baseline setup we have assumed that the authority sets interventions of the class $(\alpha, T)$ at $t=1$. Under these policies, a compliant bank optimally chooses its new lending level $I$, and funding structure $\left(\Delta e, d_{1}\right)$ compatible with regulatory capital requirements, which induces some present value of the bank to its owners, $\Pi$, and cost of the bank to the authority, $C$. Trivially, if these choices are such that conditions $\mathrm{C} 1$ and $\mathrm{C} 2$ in Lemma 1 are satisfied, then the corresponding $(\alpha, T)$ interventions will be optimal in an unconstrained sense.

\section{The optimal intervention policy}

We next use the optimality condition in Lemma 1 to characterize the authority's optimal intervention policy in our baseline setup. We split the analysis in three steps. First, we study how the disposal requirement $\alpha$ and the decision on new lending $I$ affect the cost of the compliant bank to the DGS. Second, we use this to show that a sufficiently large NPL disposal requirement induces full new lending if the bank complies. Finally, we analyze 
the bank's decision between complying and opting for resolution, and identify the cases in which the minimal optimal intervention policy includes a positive transfer in order to induce compliance and avoid resolution. ${ }^{17}$

\subsection{The cost of deposit guarantees under compliance}

Consider a bank that is required by the authority to dispose of a fraction $\alpha$ of its measure $x$ of NPLs, receiving a transfer $T$ in exchange if it complies. Suppose the bank complies and decides to undertake new lending $I$ and funding decisions described by $\left(\Delta e, d_{1}\right)$, subject to the sources and uses of funds equation in (1). The bank needs to satisfy its regulatory capital requirement at $t=1$, which can be written as

$$
(1-\alpha) x+(1-x)+I-d_{1} \geq \phi(1-\alpha) x+\gamma(1-x+I)
$$

where the LHS is the bank's available regulatory capital (the book value of its assets after disposing of a fraction $\alpha$ of the NPLs and undertaking the new lending $I$ minus the book value of its debt liabilities $d_{1}$ ) and the RHS is the bank's required regulatory capital, as determined by the fractional requirement $\phi$ on its NPLs plus the fractional requirement $\gamma$ on its old and new performing loans. ${ }^{18}$

By standard arguments, it is (weakly) optimal for the limited liability bank owners to choose the maximum amount of insured deposit funding $d_{1}$ compatible with capital regulation, since this maximizes the subsidy associated with the deposit guarantee. ${ }^{19}$ Thus, the optimal deposit base of the compliant bank is

$$
d_{1}=(1-\phi)(1-\alpha) x+(1-\gamma)(1-x+I),
$$

\footnotetext{
${ }^{17}$ By minimal we understand the optimal policy of the class $(\alpha, T)$ with the lowest $T$ and, conditional on that, with the lowest $\alpha$.

${ }^{18}$ As previously mentioned, we subsume in the requirement $\phi$ the impact on the book value of the NPLs of any valuation adjustment due to loan loss provisions. This in part explains the assumption that $\phi>\gamma$. In addition, notice that the expression in the RHS implies that the assets of the bank after $t=1$ are exclusively made of performing and non-performing loans, which means that the cash received from the NPL sale, the transfer $T$, and the new equity injection are fully used in financing the new lending and repaying some deposits (whenever $d_{1}<d_{0}$ ), as implied by (1).

${ }^{19}$ Assumption 1 implies that, if the bank only has performing and new loans, it is solvent in the two aggregate states and thus obtains no subsidy on its deposits. By a continuity argument, the same is true when the measure of NPLs $x$ is small. In those cases, the Modigliani-Miller result on capital structure indifference applies. But this implies that choosing the maximum admissible value of $d_{1}$ is also optimal in this case.
} 
which is independent from the transfer $T .^{20}$

Assumption 1 implies that a bank that satisfies its capital requirements at $t=1$ is always solvent in state $H$. Instead, the bank might be insolvent in state $L$. Denoting $\delta_{B}=$ $B_{L}-1+\gamma>0$ and $\delta_{Q}=Q_{L}-1+\phi<0$ (whose signs come from Assumption 1) the capital surplus (or, when negative, deficit) generated in state $L$ by the performing and nonperforming loans, respectively, and using the expression for $d_{1}$ in (9), we have that the required contribution from the DGS to repay deposits in state $L$ is given by

$$
\left(-\delta_{Q}(1-\alpha) x-\delta_{B}(1-x+I)\right)^{+}
$$

The expression above states that the DGS incurs some costs in state $L$ if the (positive) capital deficit associated with NPLs in such state exceeds the (positive) capital surplus of the performing loans, and that, in those cases, the payment made by the DGS equals the difference between these two quantities.

From (10) we can derive the following lemma.

Lemma 2 (Expected cost of deposit guarantees) The expected cost of the deposit guarantees enjoyed by a compliant bank subject to an intervention $(\alpha, T)$ that undertakes new lending $I$ is given by

$$
G(\alpha, I \mid x)= \begin{cases}0, & \text { if } \alpha \geq \alpha_{\text {solv }}(I, x), \\ (1-\mu)\left[\left(\delta_{B}-(1-\alpha) \delta_{Q}\right) x-\delta_{B}(1+I)\right], & \text { if } \alpha<\alpha_{\text {solv }}(I, x),\end{cases}
$$

where $\alpha_{\text {solv }}(I, x) \equiv\left(1-\frac{\delta_{B}}{-\delta_{Q}} \frac{1-x+I}{x}\right)^{+} \in[0,1)$ is the minimum fractional NPL disposal which makes the bank solvent in all states. The function $G(\alpha, I \mid x)$ is decreasing in $\alpha$ and $I$, and increasing in $x$, and strictly so if $G(\alpha, I \mid x)>0$. Finally, $\alpha_{\text {solv }}(I, x)$ is decreasing in $I$ and increasing in $x$, and strictly so if $\alpha_{\text {solv }}(I, x)>0$.

The lemma states that NPL disposal reduces the expected cost of the bank to the DGS. Retained NPLs have a regulatory capital deficit $-\delta_{Q}$ in state $L$ so a large amount of them can make the bank insolvent in that state. The NPL sale forces the owners of the compliant bank to acknowledge and absorb those losses at $t=1$, removing the subsidy amounting to $-\delta_{Q}$ per unit of NPLs that the bank would otherwise obtain from the DGS in the bad

\footnotetext{
${ }^{20}$ From (1) we have that, for a given level of new lending $I$, the transfer $T$ reduces one-by-one the additional net funding $\Delta e$ that bank owners have to provide at $t=1$.
} 
state. In fact, once the disposed fraction of NPLs exceeds the threshold $\alpha_{\text {solv }}(I, x)$ (which is increasing in the NPLs initially held by the bank), the expected cost of the deposit guarantees becomes zero. In addition, both the cost of the guarantees and the minimum NPL disposal that reduces it to zero decrease with the new lending because the new loans contribute a capital surplus $\delta_{B}$ in state $L$, and increase with the share of NPLs in the bank because of the capital deficit $-\delta_{Q}$ of these loans in state $L$.

\subsection{NPL disposal and optimal lending by the compliant bank}

We now turn to the analysis of the decision on new lending of the compliant bank and describe how it depends on the NPL disposal requirement.

For given $(\alpha, T)$, bank owners of a compliant bank choose the amount of new lending $I$ that maximizes the net value that they extract from the bank, $\Pi$. Taking into account that the overall expected cost of the compliant bank to the authority is $C=G(\alpha, I \mid x)+T$, we can use (6) to obtain the following expression for $\Pi$ :

$$
\Pi(\alpha, T, I \mid x)=E\left[Q_{s}\right] x+E\left[B_{s}\right](1-x)-(1-\gamma)+\left(E\left[B_{s}\right]-1\right) I+G(\alpha, I \mid x)+T,
$$

where we have made explicit the dependence of $\Pi$ on $\alpha, T, I$ and $x .^{21}$ Interestingly, the dependence of $\Pi$ on the fraction of NPLs that the bank is required to disposed of, $\alpha$, comes entirely through the cost of the bank to the DGS, G. As established in Lemma 2, the marginal impact of $\alpha$ on $G$ is always (weakly) negative so that bank owners never have a strict preference for NPL disposal. ${ }^{22}$

From (12) and using (11), we can find the marginal effect of new lending on the net value of the bank to its owners:

$$
\frac{\partial \Pi(\alpha, T, I \mid x)}{\partial I}= \begin{cases}E\left[B_{s}\right]-1, & \text { if } \alpha \geq \alpha_{\text {solv }}(I, x), \\ E\left[B_{s}\right]-1-(1-\mu) \delta_{B}, & \text { if } \alpha<\alpha_{\text {solv }}(I, x) .\end{cases}
$$

If the bank is always solvent after the NPL disposal and the undertaking of some new lending $I$ (that is, if $\alpha \geq \alpha_{\text {solv }}(I, x)$ ), then marginal increases in $I$ increase $\Pi$ by exactly the NPV

\footnotetext{
${ }^{21}$ Our derivation of the expression for $\Pi$ makes it unnecessary to refer to the elements that appear in the definition $\Pi=-\Delta e+E$ in (4). The expression for the funds $\Delta e$ that bank owners need to inject in the bank at $t=1$ can be obtained combining the sources and uses of funds equality in (1), the fact that $d_{0}=1-\gamma$, and the value of $d_{1}$ that satisfies (9). The expression for the continuation value of the bank's equity $E$ at $t=1$ could be obtained, residually, by adding the expression for $\Delta e$ to (12).

${ }^{22}$ This implies in particular that our implicit assumption that a compliant bank does not dispose a fraction of NPLs strictly above that required by the authority is without loss of generality.
} 
of the new loans. Since the bank repays entirely its deposits, bank owners appropriate all the marginal gains from any new investment. In contrast, if the bank is not solvent in state $L\left(\alpha<\alpha_{\text {solv }}(I, x)\right)$, part of the marginal NPV generated by the new loans contributes to reduce the expected cost of the bank to the DGS. In particular, each unit of new lending reduces $G$ in an amount $(1-\mu) \delta_{B}$, which reflects the capital surplus associated with the new loans in state $L$.

The following assumption help us focus on the most interesting parameter space region. ${ }^{23}$

\section{Assumption $3 \mu<\frac{\gamma}{B_{H}-1+\gamma}$.}

It is a matter of algebraic manipulation from (13) to show that this assumption ensures that the DGS appropriates a fraction of the total NPV of the new loans large enough to make $\partial \Pi(\alpha, T, I \mid x) / \partial I<0$ if $\alpha<\alpha_{\text {solv }}(I, x)$.

Let us analyze the bank's optimal new lending decision in the non-trivial case in which $\alpha<\alpha_{\text {solv }}(0, x)$, so that with $I=0$ the bank is not solvent in state L. We have from (13) that owners' net value $\Pi(\alpha, T, I \mid x)$ is $\mathrm{V}$-shaped with respect to the new lending $I$. For low $I$, $\Pi(\alpha, T, I \mid x)$ decreases with $I$ but the capital surplus associated with the new loans brings the bank closer to solvency in state $L$. So, for high enough $I$, the bank becomes solvent in the two states $\left(\alpha \geq \alpha_{\text {solv }}(I, x)\right.$ is satisfied) and further increases in $I$ increase $\Pi(\alpha, T, I \mid x)$. The resulting V-shape implies that bank owners find optimal to either undertake all the feasible new lending, $I=y$, or no new lending at all, $I=0$. Moreover, if $I=y$ is optimal, then such amount of new lending makes the bank solvent in the two states, so $G(\alpha, y \mid x)=0$.

Undertaking the maximal amount of new lending is optimal to bank owners if and only if $\Pi(\alpha, T, y \mid x) \geq \Pi(\alpha, T, 0 \mid x)$, which using (12) is equivalent to

$$
\left(E\left[B_{s}\right]-1\right) y \geq G(\alpha, 0 \mid x)-G(\alpha, y \mid x),
$$

which is independent from the transfer $T$. Taking into account that if bank owners find optimal to lend $I=y$ then $G(\alpha, y \mid x)=0$, we can conclude that

$$
\left(E\left[B_{s}\right]-1\right) y \geq G(\alpha, 0 \mid x)
$$

\footnotetext{
${ }^{23}$ The characterization of the optimal intervention policies when Assumption 3 does not hold and the discussion of the role played by NPL disposal in that context can be found in Appendix C.
} 
is a necessary and sufficient condition for the compliant bank to be willing to undertake new lending after the NPL disposal. This condition says that the NPV of the new lending must exceed the subsidy from the DGS that the bank forgoes if it undertakes its new lending.

From (14) we can derive the next formal result.

Lemma 3 (New lending decision of the compliant bank) Consider a bank that complies with an intervention $(\alpha, T)$. Let $\alpha_{\text {lend }}(x, y) \in[0,1)$ be zero if $\left(E\left[B_{s}\right]-1\right) y \geq G(0,0 \mid x)$ and the solution to

$$
\left(E\left[B_{s}\right]-1\right) y=G\left(\alpha_{\text {lend }}(x, y), 0 \mid x\right)
$$

otherwise. Then:

1. If $\alpha<\alpha_{\text {lend }}(x, y)$ the bank does not undertake any new lending, $I=0$.

2. Otherwise, the bank undertakes all its new lending, $I=y$. Besides, in this case, the bank becomes solvent in the two states.

Finally, $\alpha_{\text {lend }}(x, y)>0$ for $x>\frac{\delta_{B}}{\delta_{B}-\delta_{Q}}$ and $y<\frac{G(0,0 \mid x)}{E\left[B_{s}\right]-1}$, and $\alpha_{\text {lend }}(x, y)$ is increasing in $x$ and decreasing in $y$, and strictly so if $\alpha_{\text {lend }}(x, y)>0$.

The lemma shows that there are circumstances in which a sufficiently large fractional NPL disposal requirement is necessary (and sufficient) for the compliant bank to undertake its new lending. Otherwise a debt overhang problem as in Myers (1977) arises. A sufficiently large disposal forces the bank to recognize losses, removing the deposit insurance subsidy that makes the option to simply stick to the legacy assets more attractive to the bank owners than the undertaking of the new lending opportunities. In line with this logic, the lemma shows that the minimum fractional NPL disposal that induces new lending is strictly positive when the amount of NPLs in the bank is large and the size of the new lending opportunities is small. Moreover, such fraction is increasing in the amount of NPLs initially held by the bank and decreasing in the size of the new lending opportunities. Figure 1 illustrates these results.

\subsection{Optimal intervention (and the need for positive transfers)}

In this subsection we show that there exist interventions of the class $(\alpha, T)$ that satisfy the unconstrained optimality conditions in Lemma 1 and characterize the minimal optimal 
intervention. Recall that, according to Lemma 1, an intervention that induces full new lending and either has a zero cost to the authority or reduces the net value of the bank to its owners to zero is optimal.

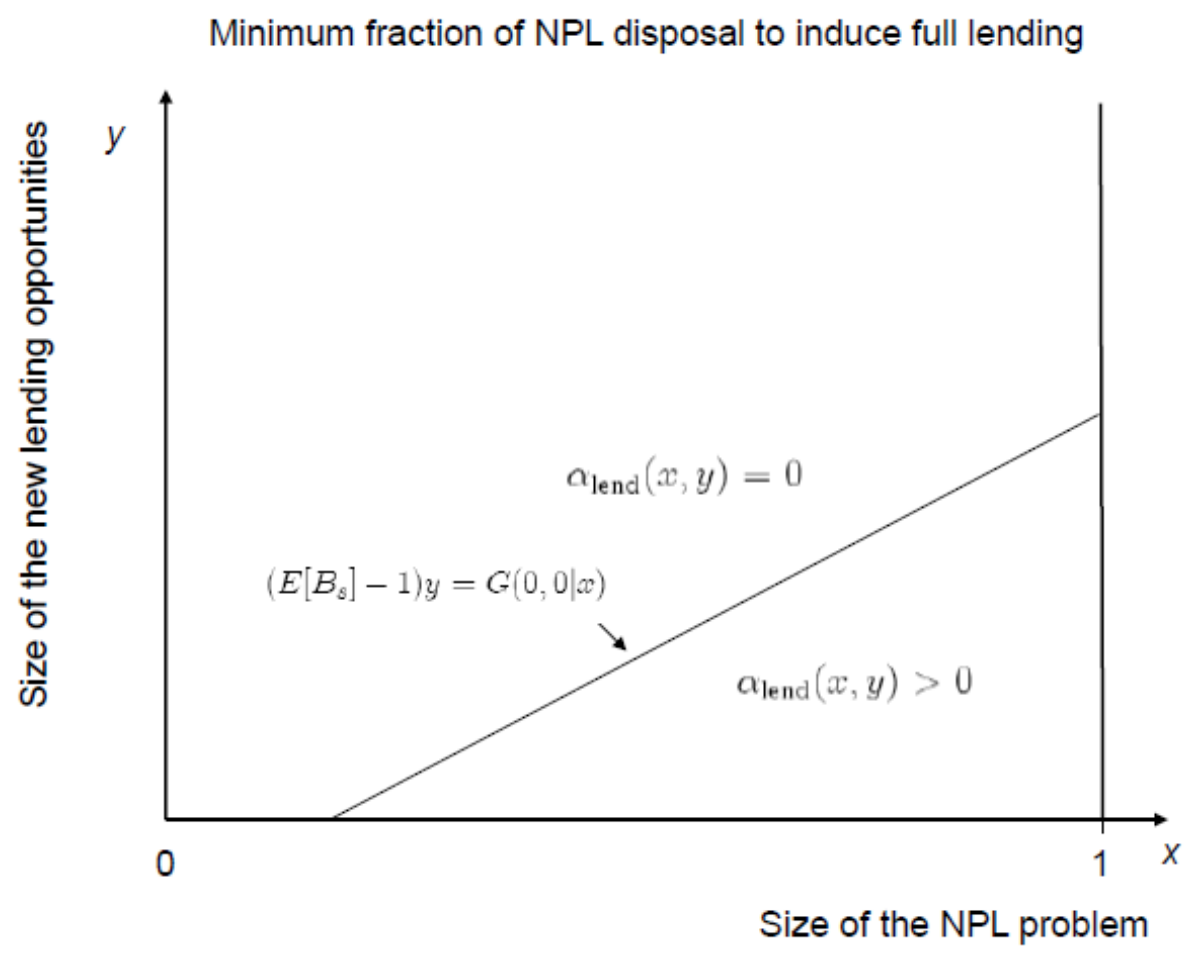

Figure 1

Let $(\alpha, T)$ be an intervention policy that leads the compliant bank to undertake its new lending opportunities in full. Lemma 3 implies that $\alpha \geq \alpha_{\text {lend }}(x, y)$ and that, after undertaking new lending in full, the bank is solvent in the two states at $t=2$. Taking into account that in case of resolution bank owners' payoff is zero, we have that they will prefer compliance to resolution if and only if $\Pi(\alpha, T, y \mid x) \geq 0$, that is,

$$
E\left[Q_{s}\right] x+E\left[B_{s}\right](1-x)-(1-\gamma)+T-\left(E\left[B_{s}\right]-1\right) y \geq 0 .
$$

Note that if all the initial loans of the bank were non-performing $(x=1)$, this condition would simplify to

$$
\left(E\left[B_{s}\right]-1\right) y+T \geq 1-\gamma-E\left[Q_{s}\right] .
$$


Taking into account that Assumption 1 implies that $1-\gamma>E\left[Q_{s}\right]$, the inequality in (17) will not be satisfied if the size $y$ of the new lending opportunities is small and the public transfer $T$ is zero. So, for $x$ close to one and $y$ close to zero, the authority cannot induce the bank to undertake investment using NPL disposal as the only tool. The reason is that NPL disposal affects in a conflicting manner the two decisions the bank takes at $t=1$, namely whether to comply or opt for resolution and, conditional on the former, how much new lending to undertake. NPL disposal reduces the subsidy received from the DGS, which reduces the debt overhang problem and incentivizes new lending should the bank be compliant. Yet, the reduction in the deposit insurance subsidy comes hand in hand with bank owners' need to inject funds in order to cover the NPL losses, which gives incentives to the limited liability protected bank owners to let the bank be resolved at the interim date.

The following proposition, which constitutes the core result of the paper, characterizes the minimal intervention policy of the class $(\alpha, T)$ which is unconstrained optimal and shows that positive public transfers solve the aforementioned conflict, when it appears:

Proposition 1 (Optimal intervention policy) There exists an intervention of the class $(\alpha, T)$ that satisfies conditions $C 1$ and C2 in Lemma 1 and is thus unconstrained optimal. The minimal unconstrained optimal intervention is $\left(\alpha^{*}(x, y), T^{*}(x, y)\right)$ with

$$
\begin{aligned}
\alpha^{*}(x, y) & =\alpha_{\text {lend }}(x, y), \text { and } \\
T^{*}(x, y) & =\left(1-\gamma-E\left[Q_{s}\right] x-E\left[B_{s}\right](1-x)-\left(E\left[B_{s}\right]-1\right) y\right)^{+} .
\end{aligned}
$$

Moreover, the expected cost of the NPL problem to the authority is just $T^{*}(x, y)$, which is increasing in $x$ and decreasing in $y$, and strictly so when $T^{*}(x, y)>0$. The following regions in the $(x, y)$ space exist and have positive measure

1. $\alpha^{*}(x, y)=0$ and $T^{*}(x, y)=0$ : for low $x$ relative to $y$.

2. $\alpha^{*}(x, y)>0$ and $T^{*}(x, y)>0$ : for high $x$ and low $y$.

3. $\alpha^{*}(x, y)=0$ and $T^{*}(x, y)>0$ : for high $x$ and medium $y$.

4. $\alpha^{*}(x, y)>0$ and $T^{*}(x, y)=0$ : for medium $x$ and low $y$, provided $\phi$ is close to $\gamma$.

Finally, an intervention policy $\left(\alpha^{\prime}(x, y), T^{\prime}(x, y)\right)$ is unconstrained optimal if and only if $\alpha^{\prime}(x, y) \geq \alpha^{*}(x, y)$ and $T^{\prime}(x, y)=T^{*}(x, y)$. 
The proposition states that an authority having fractional NPL disposal requirements and public transfers as possible intervention tools can always achieve the sufficient conditions for unconstrained optimality stated in Lemma 1, avoiding bank resolution and inducing full new lending. The minimal optimal intervention of the class $(\alpha, T)$ depends on the relationship between the measure of NPLs held by the bank prior to the intervention and the size of the bank's new lending opportunities. As illustrated in Figure 2, the proposition identifies four different regions:

- Region I. When the amount of NPLs is low relative to the size of the lending opportunities, there is no need for intervention and the cost to the authority is zero. Intuitively, the debt overhang problem is so weak that the bank has incentives to lend even without NPL disposal, and the returns at $t=2$ are sufficient to repay the deposits of the bank in the two states.

- Region II. When the bank has many NPLs and few new lending opportunities, some positive forced disposal of NPLs is necessary in order to induce the bank to lend. Moreover, to avoid that bank owners prefer resolution to compliance, the intervention needs to be complemented with positive public transfers. In the absence of intervention ( $\alpha=T=0)$, in this region the bank would be compliant with capital requirements but not undertake new lending if its NPL size is not too high, and would opt for resolution otherwise.

- Region III. There always exists a third region (with a high measure of NPLs and new lending opportunities of medium size) in which the debt overhang problem is so weak that no NPL disposal is necessary but still the authority needs to make a positive transfer to avoid resolution. The reason is that, even if NPLs are not sold, bank owners would still have to inject a lot of new equity funding to comply with capital regulation (specifically with the higher capital needs associated with NPLs). In this case the authority has to make a positive transfer to prevent resolution since bank owners would prefer the bank to be resolved rather than to contribute the required funds fully at their own cost.

- Region IV. There can also be a fourth region in which the minimal optimal intervention only requires a positive disposal requirement. In this region, the measure of NPLs is 
in a medium range, the size of the new lending opportunities is small and, in absence of intervention, the bank would avoid resolution but would not undertake new lending. This region exists if the capital requirement on NPLs is not much larger than that on performing loans (that is, if $\phi-\gamma$ is small).

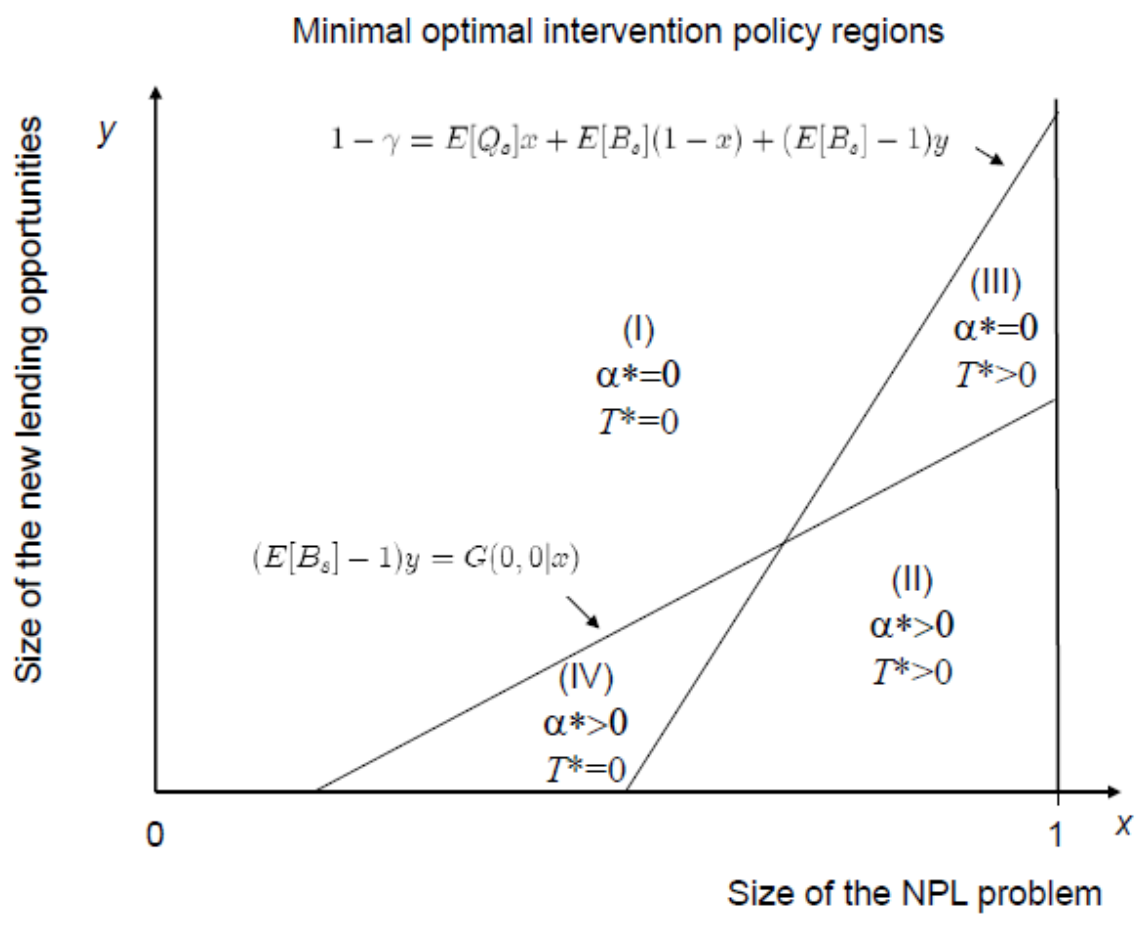

Figure 2

\subsection{Discussion of the results}

Before closing this section, we highlight several properties of the optimal $(\alpha, T)$ intervention policies and discuss the robustness of the results.

First, despite having been designed with the microprudential objective of minimizing the cost of the bank to the DGS and the taxpayers, the optimal policies also achieve the macroprudential goal of maximizing overall social surplus, as they induce the full undertaking of the bank's new lending opportunities. 
Second, whenever they feature $T^{*}>0$, these positive transfers, the forced NPLs sales, the induced new lending, and the existing capital regulation end up implying equity contributions by the bank owners such that they obtain exactly the same zero net payoffs that they would have obtained if the bank were resolved. ${ }^{24}$ Building on this, it can be shown that from an ex ante perspective the bank's moral hazard problems in loan origination are not aggravated relative to a case in which the bank expects interventions that make no use of positive transfers at the interim date (see Appendix B.1 for details).

Third, the analysis has been developed under the assumption that the fraction of NPLs with which the bank arrives at $t=1$ is observable to the authority, but it is possible to show that when the authority does not observe $x$ optimality can still be attained, after minor adaptations, with interventions of the same form (and underlying intuition) as the ones identified above (Appendix B.2).

Fourth, it is also possible to analyze the case in which, additionally to the new lending opportunities of the baseline setup, the bank has access to some alternative riskier but less profitable lending opportunities (that is, an opportunity to gamble); we can show that the key results are again robust to such an extension (Appendix B.3)

\section{Alternative forms of intervention}

In this section we explore the possibility of implementing optimal interventions using tools and procedures different from the NPL disposal requirements and public transfers analyzed in prior sections. We show that common bank resolution tools such as P\&A transactions whereby a healthy bank absorbs assets and liabilities of a troubled bank may allow optimality to be reached with a smaller NPL disposal requirement. We also show the possibility of using prudential provisioning as a substitute for NPL disposal requirements and that, in the presence of uninsured long-term debt, optimal interventions may have to rely on the partial bail in of such debt. Finally, we discuss optimal interventions in the case in which public transfers cannot be used.

In the interest of space, the discussion will focus on how some of the relevant expressions in the baseline model get modified in each of the extensions, relegating a more detailed

\footnotetext{
${ }^{24}$ In practical terms, when the optimal intervention policies exhibit $T^{*}>0$ they can be interpreted as a "tough" recovery plan with full dilution of pre-existing equity, issuance of new equity among possibly new shareholders, and some injection of public funds.
} 
presentation of the analysis to Appendix B.

\subsection{Purchase and assumption interventions}

Bank resolution frequently involves the transfer of some of the assets and liabilities of a troubled bank to a healthier bank. Such transactions, known as P\&A transactions in the US, preserve the continuity of some of the relationships of the distressed bank with its customers under the umbrella of the absorbing bank, and may be accompanied by several forms of financial support from the authority to the purchaser (from cash transfers to losssharing agreements). ${ }^{25}$ In this section we discuss how the optimal intervention policies would change in the presence of a healthier bank to which the authority can transfer the assets of the distressed bank, including the not yet undertaken new lending opportunities, and its liabilities. The analysis shows that, relative to the baseline interventions considered so far, a P\&A intervention may reduce the need for NPL disposals but not the need for public transfers and the overall cost to the authority.

Assume that at $t=1$ there exists a second bank with a portfolio consisting of $z$ units of performing loans and $(1-\gamma) z$ units of deposits. For simplicity, assume that it has no new lending opportunities. ${ }^{26}$ We refer to this bank and that in the baseline model as the strong and weak banks, respectively. We also assume that, if the strong bank purchases the weak bank, the new merged institution has access to the lending opportunities of the weak bank.

Formally, a P\&A intervention policy in this extended setting can be described by a tuple $\left(\alpha, T_{s}, T_{w}\right)$ consisting of: (i) an NPL disposal requirement $\alpha$ on the weak bank that is followed by the transfer to the strong bank of the remaining loans and all the deposits of the weak bank as well as the NPL disposal revenues; (ii) a transfer $T_{s} \geq 0$ from the authority to the owners of the strong bank; and (iii) a transfer $T_{w} \geq 0$ from the owners of the strong bank to the initial owners of the weak bank. For simplicity, we assume that the owners of the strong bank keep the entire ownership of the merged bank so that $T_{w}$ is all the value that

\footnotetext{
${ }^{25} \mathrm{P} \& \mathrm{~A}$ transactions, with or without assistance, are the most frequent method of resolution employed by the Federal Deposit Insurance Corporation (FDIC) in its role as receiver of federally insured depository institutions in the US. Under Dodd-Frank Act the FDIC is also the Orderly Resolution Authority for systemically important financial institutions whose bankruptcy might pose severe consequences for US financial stability. For a discussion of P\&A transactions and alternative bank resolution methods, see White and Yorulmazer (2014).

${ }^{26}$ Equivalently we can assume that the bank has already undertaken its new loans and variable $z$ includes them.
} 
the owners of the weak bank extract from it. ${ }^{27}$

For a given $\mathrm{P} \& \mathrm{~A}$ intervention $\left(\alpha, T_{s}, T_{w}\right)$, let $I \leq y$ be the new lending undertaken by the merged bank, $\Pi_{s}$ be the present value of the strong bank to its owners at $t=1$ (net of any equity injection or dividend payment at that date), $\Pi_{w}$ be the value that the owners of the weak bank obtain from the intervention, and $C$ the cost of the NPL problem to the authority (which amounts to the transfer $T_{w}$ and the expected cost of guaranteeing the deposits of the merged bank). By definition, $\Pi_{w}=T_{w}$.

We assume that the authority cannot force the strong bank to participate in the P\&A intervention, which implies

$$
\Pi_{s} \geq \bar{\Pi}_{s}=E\left[B_{s}\right] z-(1-\gamma) z
$$

where $\bar{\Pi}_{s}$ is the net value of the strong bank to its owners if the two banks do not merge.

The cost $C$ of the NPL problem to the authority in (7) can be adapted to this extended setup as follows:

$$
C=\left(\Pi_{s}-\bar{\Pi}_{s}\right)+\Pi_{w}-\left(E\left[B_{s}\right]-1\right) I-\left(E\left[Q_{s}\right] x+E\left[B_{s}\right](1-x)-d_{0}\right),
$$

where only the terms corresponding to bank owners' values change. From (19) and $\Pi_{w} \geq 0$, the analogous to Lemma 1 states that a P\&A intervention that induces $I=y$ and that, if it leads to $C>0$, then it involves $\Pi_{w}=0$ and $\Pi_{s}=\bar{\Pi}_{s}$, is optimal. This implies, in particular, that $\mathrm{P} \& \mathrm{~A}$ intervention policies cannot reduce the cost of the weak bank to the authority relative to that obtained in the baseline setup.

Analogously to (10), the expression for cost of the deposit guarantees on the merged bank in state $L$ is

$$
\left(-\delta_{Q}(1-\alpha) x-\delta_{B}(1-x+I+z)\right)^{+},
$$

which includes a new term in $z$ that reflects how the performing loans in the initial balance sheet of the strong bank contribute to offset the capital deficit associated with the NPLs of the weak bank. The implied reduction in the value of the deposit guarantees improves the incentives of the merged bank (relative to the weak bank) to undertake the new lending, and reduces the minimum fractional NPL disposal needed to induce lending (possibly to zero if the acquiring bank is sufficiently strong).

\footnotetext{
${ }^{27}$ In our setup, practical implementations in which $T_{w}$ were paid by giving the owners of the weak bank an ownership stake in the strong bank would be equivalent.
} 
Thus, optimal P\&A interventions may involve a lower minimum NPL disposal requirement than in our baseline setup. However, the owners of the strong bank will have to be compensated for the contribution of their good loans to reducing $G$, which means that eventually the transfer paid to the strong bank owners $T_{s}$ will have to be as large as the transfer $T^{*}$ of the baseline interventions. ${ }^{28}$

\subsection{Interventions based on provisioning}

A key parameter in our model is the regulatory capital $\phi$ the bank is required to have at $t=1$ per unit of retained NPLs. In Section B.5 of the Appendix we explain in detail how parameter $\phi$ can be interpreted as capturing the combined effect of provisioning and capital requirements and show that adding a prudential adjustment to NPL provisions is equivalent to increasing $\phi$.

Elaborating on this, in this section we assume that accounting standards and the minimum regulatory capital requirement on NPLs determine a minimum exogenous value $\phi_{0}$ for $\phi$, and consider interventions of the type $(\phi, T)$, where $\phi \geq \phi_{0}$ is interpreted as the result of adding a prudential adjustment to NPL provisions and $T$ is a transfer as in the baseline model.

Analogously to (10), the expression for the cost incurred by the DGS in state $L$ is now

$$
\left(\left(1-Q_{L}-\phi\right) x-\delta_{B}(1-x+I)\right)^{+}
$$

This expression is decreasing in the overall NPL prudential requirement $\phi$ similarly to the way the expression in (10) is decreasing in the NPL disposal requirement $\alpha$. So both policy tools have the power to reduce the overall capital deficit associated with the NPLs and, thereby, encourage the bank to undertake its new lending. This also implies that interventions of the type $(\phi, T)$ can achieve the optimality condition in Lemma 1 and hence solve the legacy problem at the same minimum cost for the authority than $(\alpha, T)$ policies. So, in our model, disposal and provisioning requirements are perfect substitutes as tools to solve banks' legacy problems at the lowest cost.

\footnotetext{
${ }^{28}$ If NPL sales involve any cost (e.g. due to the lack of liquidity of the NPL market) that can avoided if the NPLs are retained by the merged bank, such gains would obviously translate into reducing the cost of the intervention to the authority. These costs may then explain why, in some circumstances, authorities strictly prefer P\&A interventions to other forms of intervention.
} 
However, in practice, there may be situations in which the perfect substitutability between the two instruments breaks down, making one of the two strictly preferable. First, if the authority does not observe the measure of NPLs with which the bank enters the interim date (as in the extension conducted in Appendix B.2), NPL disposal would dominate prudential provisioning as the former would be more effective in deterring the bank' incentives to overstate its privately observed amount of NPLs in order to obtain transfers from the authority. Second, if the disposal of NPLs is done at a price that is below their fundamental value (because, e.g., investors with the capability to manage these assets have a high opportunity cost of funds), then prudential provisioning would dominate NPL disposals as the latter would lead to a reduction in the overall value of the bank assets and thus increase the public transfers necessary to avoid resolution.

\subsection{Long-term debt and the need for bail-in arrangements}

In the baseline model we assume that all the bank debt consists of deposits insured by the DGS and show that it is always optimal to avoid resolution and to induce the full undertaking of the new lending opportunities. We have interpreted these results as implying

the alignment between the traditional microprudential objective of minimizing the cost of the safety net and the macroprudential objective of maximizing aggregate welfare. In this section we extend the model to allow for the presence of some outstanding long-term (LT) debt at the interim date and show that the two objectives remain aligned provided that the LT debt is bailinable (as it is, e.g., in the EU bank resolution regime). Otherwise, minimizing the cost of the legacy problem to the authority may sometimes be incompatible with inducing new lending, as in these cases LT debtholders would appropriate a disproportionate fraction of its value, in the detriment of the authority.

Consider that the capital structure of the bank at $t=0$ includes, in addition to insured deposits and owners' equity, some uninsured LT debt that promises a repayment $h_{0}$ at $t=2$. We assume, as in the baseline version of the model, that the bank's overall leverage equals the maximum compatible with regulation, $d_{0}+h_{0}=1-\gamma$, and that LT debt is junior to insured deposits.

The authority's objective is still to minimize the cost of the bank to the DGS and the taxpayer. Moreover, we assume that, if not in conflict with such main goal, the authority 
prefers policies that maximize aggregate welfare or, equivalently, that maximize new lending. ${ }^{29}$ Finally, in addition to setting a NPL disposal requirement $\alpha$ and a transfer $T$, we allow the authority to bail in the LT debt as part of its intervention policy. We model this policy tool as the capacity to fix a new promised repayment $h_{1} \leq h_{0}$ for the LT debt. ${ }^{30}$

An intervention policy is thus described by a tuple $\left(\alpha, h_{1}, T\right)$ with $h_{1} \leq h_{0}$. Realistically, we assume that the bail-in of LT debt must satisfy two institutional conditions. ${ }^{31}$ First, it must respect the seniority of debt relative to equity, meaning that if $h_{1}<h_{0}$ then the intervention policy must induce a net value for the bank owners equal to zero. Second, it must satisfy the no-creditor-worse-off criterion, meaning that the value of the new promise $h_{1}$ on LT debt induced by the intervention policy, denoted with $H$, must satisfy

$$
H \geq H_{\text {res }}
$$

where $H_{\text {res }}=\min \left(\max \left(x E\left[Q_{s}\right]+(1-x) E\left[B_{s}\right]-d_{0}, 0\right), h_{0}\right)$ is the value of the outstanding promise $h_{0}$ if the bank were resolved at $t=1 .^{32}$

For a given new investment level $I$, the expression for the cost $C$ of the bank to the authority analogous to (7) can be written as:

$$
C=\Pi+H-\left(E\left[B_{s}\right]-1\right) I-\left(E\left[Q_{s}\right] x+E\left[B_{s}\right](1-x)-d_{0}\right) .
$$

From (23), the analogous to Lemma 1 states that an intervention policy that induces $I=y$ and that, if it leads to $C>0$, then it also leads to $\Pi=0$ and $H=H_{\text {res }}$, is optimal. The last condition ensures that the LT debtholders appropriate no value from the new lending, since from (24) this would imply an increase in the cost of the bank to the authority.

As in the baseline model, it can be proven that there are policies $\left(\alpha, h_{1}, T\right)$ compatible with the sufficient optimality conditions, that is, optimal intervention policies avoid resolution, induce full new lending, and require some bail-in of LT debt if public transfers are

\footnotetext{
${ }^{29}$ In the baseline model this subsidiary objective is implied by the primary objective, as stated in Lemma 1. In this extension, the subsidiary objective constraints the authority to choose policies that avoid resolution and/or remove the debt overhang problem whenever they imply no additional cost to the authority.

${ }^{30}$ In the EU, under the Bank Recovery and Resolution Directive (BRRD), authorities have the power to bail-in some of the debt liabilities of a failing bank. In the context of the BRRD, "resolution" refers to the authority's recovery plan for a "failing or likely to fail bank." In the context of this extension, we interpret BRRD resolutions as one of the policy interventions available to the authority (and one not necessarily involving the liquidation of the bank). In contrast, what we referred to as "resolution" throughout the paper is closer to just the orderly liquidation of the bank.

${ }^{31}$ All the results in this extension are also valid without these institutional constraints but we introduce them to emphasize that the results are compatible with standard constraints on authorities' bail-in powers.

${ }^{32}$ The expression for $H_{\text {res }}$ takes into account that insured deposits are senior to LT debt.
} 
realized. However, inducing new lending is not always optimal when the authority is not empowered to restructure LT debt. In fact, the public transfer needed to induce new lending may not minimize the cost to the authority because a too large fraction of the NPV of the new lending is appropriated by the LT debtholders. ${ }^{33}$

\subsection{Interventions without public transfers}

In this section we analyze the optimal intervention policy when the use of public transfers at $t=1$ is not permitted. Here $T=0$ and the authority can only use the NPL disposal requirement $\alpha$ to minimize the only component of the authority's cost in this case: the expected cost of the bank's deposit guarantees, $G$.

Consider the interesting case in which the optimal intervention in the baseline setup features $T^{*}>0$, which happens when the fraction of NPLs in the bank is high and the size of new lending opportunities is medium or low (regions II and III in Proposition 1). In this situation the authority with only access to $\alpha$ policies cannot anymore avoid resolution and induce new lending at the same time. So it has to decide between the two. In order to (attempt to) avoid resolution, the authority would have to set the NPL disposal requirement $\alpha$ below the full lending threshold $\alpha^{*}=\alpha_{\text {lend }}(x, y)$. The reduction in $\alpha$ might not be able to induce the bank to be compliant but, if it does, by definition the net value of the bank to its owners must be positive. Since the bank does not undertake new lending the expression for the cost $C=G$ for the authority in (7) implies that the rise in bank owners' value $\Pi$ must come at the expense of an increase in the DGS liability $G$. But then the authority would prefer any disposal policy that leads to resolution. ${ }^{34}$

Compared to the optimal $(\alpha, T)$ policies, the cost of the NPL problem to the authority increases by exactly the NPV of the lending opportunities which are foregone when the bank is resolved. Moreover, the funds that the DGS must contribute to fully repay the deposits of the resolved bank exceed the size of the transfer $T^{*}>0$ associated with the optimal $(\alpha, T)$

\footnotetext{
${ }^{33}$ Thus, there may be a conflict between microprudential and macroprudential goals, as discussed by Alessandri and Panetta (2015), among others. To the best of our knowledge, we are the first to provide a model in which the possibility to bail-in uninsured debt helps resolve this conflict.

${ }^{34}$ It can be shown that, simultaneously, there could be exactly one optimal policy that avoids resolution. This policy would also involve no lending and leave bank owners with a zero net continuation value (no rents), so it would be payoff-equivalent to resolution for both bank owners and the authority. The policy would exhibit $\alpha<\alpha^{*}$ and would exist only if $x$ is not too high. A detailed description of this equivalent optimal constrained intervention is omitted for brevity.
} 
policy. Altogether, these results suggest that restrictions to direct state aid when dealing with a NPL problem may backfire, leading to increases in the cost of the bank to the DGS that exceed the money saved to the taxpayers.

\section{Conclusion}

Damaged legacy assets compromise banks' solvency and constitute a contingent liability for national DGSs. Besides, they may be an obstacle to the origination of new socially valuable lending by the affected banks. To address the NPL problem, EU authorities have launched an ambitious action plan that considers the possibility of using instruments such as guidance of NPL disposal or stringent calendars for the full provisioning and write-off of the damaged loans directed to either induce banks to dispose of their NPLs or to ensure the existence of loss absorbing capacity against the worst possible realizations of the returns on the retained NPLs. In the US accounting and regulatory practices encouraging a quicker disposal or full write-off of bad loans, as well as the frequent use of P\&A transactions in the resolution of weak banks have a longer tradition.

We have provided a simple analytical framework in which these instruments can be part of an optimal intervention policy regarding legacy problems among regulated banks. Compulsory NPL sales or prudential provisioning, force bank owners to absorb the losses associated with the legacy assets and to give up the option-like subsidy associated with the access to insured deposit funding. If banks comply with the requirements implied by these policies, the obstacle to the undertaking of profitable new lending can be removed. However, sometimes bank owners will not be willing to assume the burden of the intervention and will simply prefer that their bank gets resolved. The analysis reveals that in the latter case a policy aimed at minimizing the joint cost of the legacy problem to the DGS and the taxpayers should combine tough requirements on NPL disposal or provisioning with the minimal transfers needed to avoid resolution. We show that, when optimally designed, these "stick and carrot" policies avoid bank resolution, induce new lending, and do not leave rents to the bank owners. Quite intuitively, the NPV of the new lending undertaken by the unresolved bank once freed from the legacy problem contributes to reduce the cost of the problem to the DGS and the taxpayers.

The results in the paper have a number of relevant implications for the design of policy 
interventions to deal with banks' legacy problems. First, both the minimal fraction of NPLs that each bank should be required to dispose of or fully write-off, and the transfers that its owners may have to receive in exchange are increasing in each bank's initial fraction of NPLs. So, instead of a one-size-fits-all approach, these results suggest the convenience of more decisive interventions (along both the stick and the carrot dimensions) on banks with more severe problems.

Second, we find that when banks have a substantial fraction of their funding in the form of uninsured long-term debt, the partial restructuring of this debt using bail-in provisions is an intervention tool that valuably complements compulsory NPL disposals and public transfers. Such restructuring avoids an excessive appropriation of the NPV of the new lending by the long-term debtholders ensuring that inducing new lending is a feature of the policies aimed to minimize the cost of the legacy problem to the DGS and the taxpayers.

Finally, the analysis reveals potential shortcomings associated with the existence of limitations to the involvement of public funds in the solution of legacy problems. It shows, in particular, that prohibiting the transfers associated with the optimal interventions in the cases where the legacy problems are more severe increases the expected cost to the DGS in excess to the forbidden public transfers. The intuition is that in the absence of public transfers it might not be possible to induce new lending among the affected banks and the NPV of such lending would have reduced the expected cost of the bank to the DGS. Importantly, the optimal interventions that we have characterized leave no rents to bank shareholders so they are not a source of moral hazard problems such as those typically alluded to justify no bail-out provisions. 


\section{References}

Acharya, Viral, and Tanju Yorulmazer (2007) "Too many to fail - An analysis of timeinconsistency in bank closure policies," Journal of Financial Intermediation, 16, 1-31.

Admati, Anat, Peter De Marzo, Martin Hellwig, and Paul Pfleiderer (2018) "The leverage ratchet effect," Journal of Finance, 73, 145-198.

Aghion, Philip, Patrick Bolton, and Steven Fries (1999) "Optimal Design of Bank Bailouts: The Case of Transition Economies," Journal of Institutional and Theoretical Economics, 155, 51-70.

Bahaj, Saleem, and Frederic Malherbe (2017) "A positive analysis of bank behaviour under capital requirements," working paper, London Business School, March 2017.

Basel Committee on Banking Supervision (2017), Basel III: Finalising post-crisis reforms, December.

Berglöf, Erik, and Gérard Roland (1995) "Bank Restructuring and Soft Budget Constraints in Financial Transition," Journal of the Japanese and International Economies, 9, 354375 .

Black, Fischer, and Myron Scholes (1973) "The pricing of options and corporate liabilities," Journal of Political Economy, 81, 637-654.

Bruche, Max, and Gerard Llobet (2013) "Preventing zombie lending," Review of Financial Studies, 27, 923-956.

Council of the European Union (2017), Report of the FSC Subgroup on Non-Performing Loans, July.

Diamond, Douglas, and Raghuram Rajan (2011) "Fear of fire sales, illiquidity seeking, and credit freezes," Quarterly Journal of Economics, 126, 557-591.

Diamond, Douglas, and Raghuram Rajan (2012) "Illiquid banks, financial stability, and interest rate policy," Journal of Political Economy, 120, 552-591.

European Banking Authority (2016), Dynamics and Drivers of Non-performing Exposures in the EU Banking Sector, July.

European Central Bank (2017), Guidance to Banks on Non-performing Loans, March.

European Systemic Risk Board (2017), Resolving Non-performing Loans in Europe, July. 
Farhi, Emmanuel, and Jean Tirole (2012) "Collective moral hazard, maturity mismatch, and systemic bailouts," American Economic Review, 102, 60-93.

Freixas, Xavier (1999) "Optimal bail-out, conditionality and creative ambiguity," CEPR Discussion Papers.

Keister, Todd (2016) "Bailouts and financial fragility," Review of Economic Studies, 83, 704-736.

Merton, Robert (1974) "On the pricing of corporate debt: The risk structure of interest rates," Journal of Finance, 29, 449-70.

Mitchell, Janet (2001) "Bad Debts and the Cleaning of Banks' Balance Sheets: An Application to Transition Economies," Journal of Financial Intermediation, 10, 1-27.

Myers, Stewart (1977) "Determinants of corporate borrowing," Journal of Financial Economics, 5, 147-175.

Philippon, Thomas, and Philipp Schnabl (2013) "Efficient recapitalization," Journal of Finance, 68, 1-42.

White, Phoebe, and Tanju Yorulmazer (2014) "Bank resolution concepts, trade-offs, and changes in practices," FRBNY Economic Policy Review, December, 153-173. 


\section{Appendix}

\section{A Proofs}

This appendix contains the proofs of the propositions included in the body of the paper.

Proof of Lemma 1 We first prove that there is no policy leading to a strictly negative cost to the authority. Suppose on the contrary that the policy $\left(\alpha, T, I, \Delta e, d_{1}\right)$ induces a negative cost $C<0$. Let $\Pi$ be the net value of the bank to its owners under such intervention. The only way in which $C<0$ can arise is if the bank is not compliant with the policy, so that it is resolved at $t=1$ at a gain to the DGS. This can only happen when the bank asset value exceeds the repayments due to depositors, that is, when

$$
E\left[Q_{s}\right] x+E\left[B_{s}\right](1-x)>1-\gamma
$$

Denote by $\Pi^{\prime}$ and $C^{\prime}$ the value to the bank owners and the cost to the authority if the bank were compliant. Equations (6) and (25), and the fact that if the bank is not resolved at $t=1$ then $C^{\prime} \geq 0$, imply that $\Pi^{\prime}>0$. But then letting the bank being resolved would not be optimal to its owners. So it is not possible to have interventions leading to $C<0$.

Suppose now $\left(\alpha, T, I, \Delta e, d_{1}\right)$ satisfies the conditions in the lemma and is not optimal. Let the net value to bank owners and the cost to the authority under such policy be again denoted by $\Pi$ and $C$, respectively. If $C=0$ then, taking into account the previous result that the cost can never be strictly negative, we have that the policy is optimal.

Suppose instead that $C>0$. Then, to satisfy the sufficient conditions stated in the lemma, we must have $\Pi=0$. Let $\left(\alpha^{*}, T^{*}, I^{*}, \Delta e^{*}, d_{1}^{*}\right)$ be an optimal policy and let $C^{*}, \Pi^{*}$,

and $\widetilde{I} \in\left\{0, I^{*}\right\}$ denote the payoffs and lending decision induced by this policy (where $\widetilde{I}=0$ would mean that the bank is not compliant in which case $\left.\Pi^{*}=0\right)$. For $\left(\alpha, T, I, \Delta e, d_{1}\right)$ not to be optimal, we should have $C^{*}<C$. But then we would have

$$
\begin{gathered}
\left(E\left[Q_{s}\right] x+E\left[B_{s}\right](1-x)-d_{0}\right)+\left(E\left[B_{s}\right]-1\right) \widetilde{I}=\Pi^{*}-C^{*} \geq \Pi-C^{*} \\
>\Pi-C=\left(E\left[Q_{s}\right] x+E\left[B_{s}\right](1-x)-d_{0}\right)+\left(E\left[B_{s}\right]-1\right) y .
\end{gathered}
$$

where we have sequentially used equality (6), $\Pi^{*} \geq \Pi=0, C^{*}<C$, and equality (6) again. However, (26) implies $\widetilde{I}>y$, which cannot happen.

Proof of Lemma 2 The compliant bank deposit base $d_{1}$ is given by (9). Assumption 1 then implies that the bank repays entirely its deposits in state $H$ and its cost to the DGS is

$$
\begin{aligned}
G(\alpha, I \mid x) & =(1-\mu)\left(d_{1}-Q_{L}(1-\alpha) x+B_{L}(1-x+I)\right)^{+} \\
& =(1-\mu)\left(\left(\delta_{B}-(1-\alpha) \delta_{Q}\right) x-\delta_{B}(1+I)\right)^{+}
\end{aligned}
$$


Let $\alpha_{\text {solv }}(I, x)$ be defined as the solution to

$$
\left(\delta_{B}-\left(1-\alpha_{\text {solv }}(I, x)\right) \delta_{Q}\right) x-\delta_{B}(1+I)=0
$$

whenever it is non-negative, and $\alpha_{\text {solv }}(I, x)=0$ otherwise. It is a matter of algebraic manipulation to check that the resulting analytical expression for $\alpha_{\text {solv }}(I, x)$ coincides with that stated in the lemma.

Proof of Lemma 3 We have argued in the main text preceding the lemma that the compliant bank finds optimal to undertake its new lending in full if (14) holds, and not to undertake any new lending otherwise. Lemma 2 shows that $G(\alpha, 0 \mid x)$ is decreasing in $\alpha$ and strictly so if $G(\alpha, 0 \mid x)>0$. Moreover, for $\alpha \in\left[\alpha_{\text {solv }}(0, x), 1\right)$, we have that $G(\alpha, 0 \mid x)=0$. The results in the lemma follow immediately from these properties.

Proof of Proposition 1 Let $\left(\alpha^{*}, T^{*}\right)$ be the intervention policy described as the minimal unconstrained optimal one in the statement of the proposition, and $\Pi^{*}$ and $C^{*}$ be the associated net expected payoff to bank owners and cost to the authority, respectively. From Lemma 3 we have that the intervention induces full new lending conditional on the bank being compliant and that the bank is solvent in the two states after undertaking its new lending. Moreover, by the way $T^{*}$ is defined in (18), inequality (16) is satisfied so the bank indeed finds optimal to be compliant and lend in full. Also, by construction if $T^{*}>0$ then inequality (16) is binding, which means that $\Pi^{*}=0$. We deduce that $C^{*}=T^{*}$ and we conclude that either $C^{*}=0$ or $C^{*}=T^{*}>0$ in which case $\Pi^{*}=0$. Hence $\left(\alpha^{*}, T^{*}\right)$ satisfies the two sufficient criteria for optimality in Lemma 1, so the policy is unconstrained optimal.

We now proceed to characterize the unconstrained optimal interventions of the class $(\alpha, T)$. The same arguments as those conducted above imply that any policy $\left(\alpha^{\prime}, T^{*}\right)$ with $\alpha^{\prime} \geq \alpha^{*}$ also satisfies the criteria for optimality in Lemma 1 and is thus unconstrained optimal.

Let $\left(\alpha^{\prime}, T^{\prime}\right)$ be an unconstrained optimal policy and let $\Pi^{\prime}, C^{\prime}$ be the associated net expected payoff to bank owners and cost to the authority, respectively. By the optimality assumption we have $C^{\prime}=T^{*}$.

Suppose that $\alpha^{\prime} \geq \alpha^{*}$. Then the policy induces a compliant bank to undertake full new lending and to be solvent in the two states. If the bank decides to be compliant, then the cost for the authority is $C^{\prime}=T^{\prime}$, which implies $T^{\prime}=T^{*}$. If the bank decides not to be compliant, then $\Pi^{\prime}=0$ and from (7) we have

$$
C^{\prime}=1-\gamma-E\left[Q_{s}\right] x-E\left[B_{s}\right](1-x) .
$$

Comparing this expression with the expression for $T^{*}$ in (18), we have that $C^{\prime}=T^{*}$ is equivalent to

$$
1-\gamma=E\left[Q_{s}\right] x-E\left[B_{s}\right](1-x) \Leftrightarrow C^{\prime}=0
$$


Suppose that following the intervention $\left(\alpha^{\prime}, T^{\prime}\right)$, the bank complies and undertakes some positive lending $I>0$. Let $\Pi^{\prime \prime}$ be the payoff for the bank owners under such sequence of actions. From (6) we have that

$$
\Pi^{\prime \prime}=\left(E\left[Q_{s}\right] x+E\left[B_{s}\right](1-x)-(1-\gamma)\right)+\left(E\left[B_{s}\right]-1\right) I+T^{\prime}>0
$$

where in the inequality we have used (27), $T^{\prime} \geq 0$ and $I>0$. But under $\Pi^{\prime \prime}>0=\Pi^{\prime}$ the bank would find optimal to be compliant.

Suppose that $\alpha^{\prime}<\alpha^{*}$. This in particular requires $\alpha^{*}>0$ and implies that the optimal policy $\left(\alpha^{\prime}, T^{\prime}\right)$ does not induce lending (regardless of compliance or not). Using this, and that $\Pi^{\prime} \geq 0$, we have from $(7)$ that

$$
C^{\prime} \geq 1-\gamma-E\left[Q_{s}\right] x-E\left[B_{s}\right](1-x)
$$

From the definition of $T^{*}$ in (18), the inequality implies that $C^{\prime}=T^{*}$ is again equivalent to (27), so that the inequality needs to be binding, that is $\Pi^{\prime}=0$. The same argument as above then leads to a contradiction, so that $\alpha^{\prime}<\alpha^{*}$ cannot be part of an unconstrained optimal policy.

We conclude that a policy $\left(\alpha^{\prime}, T^{\prime}\right)$ is unconstrained optimal if and only if $\alpha^{\prime} \geq \alpha^{*}$ and $T^{\prime}=T^{*}$, which in particular implies that $\left(\alpha^{*}, T^{*}\right)$ is the minimal unconstrained optimal policy of the class $(\alpha, T)$.

We now proceed to show the existence of the four regions in the $(x, y)$ space mentioned in the proposition. Let us define the following lines in the $(x, y)$ space:

$$
\begin{aligned}
y_{\alpha^{*}=0}(x) & =\frac{(1-\mu)\left[\left(\delta_{B}-\delta_{Q}\right) x-\delta_{B}\right]}{E\left[B_{s}\right]-1}, \\
y_{T^{*}=0}(x) & =\frac{1-\gamma+\left(E\left[B_{s}\right]-E\left[Q_{s}\right]\right) x-E\left[B_{s}\right]}{E\left[B_{s}\right]-1} .
\end{aligned}
$$

From Lemmas 2 and 3, and the definition of $\left(\alpha^{*}, T^{*}\right)$ in (18), we have that for $x, y \geq 0$

$$
\begin{aligned}
& \alpha^{*}=0 \text { if and only if } y \geq y_{\alpha^{*}=0}(x), \\
& T^{*}=0 \text { if and only if } y \geq y_{T^{*}=0}(x) .
\end{aligned}
$$

We also have that

$$
y_{\alpha^{*}=0}(0)<0, y_{T^{*}=0}(0)<0,
$$

which, from (29), implies that region $I$ exists and has positive measure. Moreover, we have that

$$
\begin{gathered}
0<\frac{d y_{\alpha^{*}=0}}{d x}=\frac{(1-\mu)\left(\delta_{B}-\delta_{Q}\right)}{E\left[B_{s}\right]-1}=\frac{(1-\mu)\left(B_{L}+\gamma-\left(Q_{L}+\phi\right)\right)}{E\left[B_{s}\right]-1} \\
<\frac{(1-\mu)\left(B_{L}-Q_{L}\right)}{E\left[B_{s}\right]-1}<\frac{E\left[B_{s}\right]-E\left[Q_{s}\right]}{E\left[B_{s}\right]-1}=\frac{d y_{T^{*}=0}}{d x}
\end{gathered}
$$


where he have used $\delta_{B}=B_{L}-1+\gamma, \delta_{Q}=Q_{L}-1+\phi, B_{H}>Q_{H}$, and $\phi>\gamma$. The inequality implies that $(x, y)$ belongs to region $\mathrm{I}$ for low $x$ relative to $y$.

In addition, we have that

$$
\begin{aligned}
y_{T^{*}=0}(1) & =\frac{1-\gamma-E\left[Q_{s}\right]}{E\left[B_{s}\right]-1} \geq \frac{(1-\mu)\left(1-\gamma-Q_{L}\right)}{E\left[B_{s}\right]-1} \\
& >\frac{(1-\mu)\left(1-\phi-Q_{L}\right)}{E\left[B_{s}\right]-1}=\frac{-(1-\mu) \delta_{Q}}{E\left[B_{s}\right]-1}=y_{T^{*}=0}(1)>0 .
\end{aligned}
$$

The inequality implies that there exist both region II and III and that have positive measure. Moreover, the inequality implies $(x, y)$ belongs to region II for high values of $x$ and low values of $y$, and belongs to region III for high values of $x$ and medium values of $y$.

Finally, let $x_{\alpha^{*}=0}$ and $x_{T^{*}=0}$, be defined as

$$
\begin{aligned}
y_{\alpha^{*}=0}\left(x_{\alpha^{*}=0}\right) & =0 \Leftrightarrow(1-\mu)\left[\left(\delta_{B}-\delta_{Q}\right) x_{\alpha^{*}=0}-\delta_{B}\right]=0, \\
y_{T^{*}=0}\left(x_{T^{*}=0}\right) & =0 \Leftrightarrow 1-\gamma+\left(E\left[B_{s}\right]-E\left[Q_{s}\right]\right) x_{T^{*}=0}-E\left[B_{s}\right]=0 .
\end{aligned}
$$

From inequality (30) we have that region IV exists if and only if $x_{\alpha^{*}=0}<x_{T^{*}=0}$. For $\phi \rightarrow \gamma$ we have that

$$
\begin{gathered}
1-\gamma+\left(E\left[B_{s}\right]-E\left[Q_{s}\right]\right) x_{T^{*}=0}-E\left[B_{s}\right]=0=(1-\mu)\left[\left(\delta_{B}-\delta_{Q}\right) x_{\alpha^{*}=0}-\delta_{B}\right]= \\
=(1-\mu)\left[\left(1-\phi-Q_{L}\right) x_{\alpha^{*}=0}-\left(1-\gamma-B_{L}\right)\left(1-x_{\alpha^{*}=0}\right)\right]= \\
=(1-\mu)\left[1-\gamma-Q_{L} x_{\alpha^{*}=0}-B_{L}\left(1-x_{\alpha^{*}=0}\right)\right]> \\
>E\left[1-\gamma-Q_{s} x_{\alpha^{*}=0}-B_{s}\left(1-x_{\alpha^{*}=0}\right)\right]= \\
=1-\gamma+\left(E\left[B_{s}\right]-E\left[Q_{s}\right]\right) x_{\alpha^{*}=0}-E\left[B_{s}\right]
\end{gathered}
$$

where in the last inequality we have used that

$$
1-\gamma-Q_{L} x_{\alpha^{*}=0}-B_{L}\left(1-x_{\alpha^{*}=0}\right)=0 \Rightarrow 1-\gamma-Q_{H} x_{\alpha^{*}=0}-B_{H}\left(1-x_{\alpha^{*}=0}\right)<0
$$

Looking at the expressions at the extremes of the chain of inequalities in (31), we conclude that $x_{\alpha^{*}=0}<x_{T^{*}=0}$.

\section{B Details on extensions}

\section{B.1 Initial capital structure and loan monitoring decisions}

We have thus far taken both the bank's deposit choice $d_{0}$ at $t=0$ and its fraction of NPLs at $t=1$ as given. In this section we analyze how the two are determined by the bank's optimal capital structure and (unobservable) loan monitoring decisions at $t=0$. We find that the bank finds optimal to issue as much deposits as allowed by regulation to maximize 
expected subsidies from the authority, which justifies our assumption $d_{0}=1-\gamma$ in the baseline analysis. Besides, we show that moral hazard problems on loan monitoring are not aggravated by the use of positive transfers in optimal intervention policies relative to interventions designed to avoid public transfers at the interim date. Interestingly, a policy of no intervention when legacy problems arise may aggravate moral hazard problems on loan monitoring and make legacy problems more likely.

We assume that at $t=0$ the bank chooses the initial amount of deposits $d_{0}$ subject to the regulatory constraint $d_{0} \leq 1-\gamma$. After investing in one unit of loans, monitoring can reduce the likelihood that the loans become non-performing at $t=1$. Specifically, bank owners by choosing a monitoring level $m \in[0,1]$ at at a private cost $c(m)$ at $t=0$ make the fraction of NPLs in the bank at $t=1$ be $x_{1}=0$ with probability $m$ and $x_{1}=x>0$ otherwise. To focus on the interesting situation in which optimal intervention policies may feature positive transfers, we assume:

Assumption $4 E\left[Q_{s}\right] x+E\left[B_{s}\right](1-x)+\left(E\left[B_{s}\right]-1\right) y<1-\gamma$.

In addition, we assume that bank owners' disutility cost of monitoring is increasing and convex, and satisfies the Inada-type conditions that guarantee a unique interior solution in $m$ :

Assumption $5 c(0)=0, c^{\prime}(0)=0$, and $c^{\prime}(1)>x\left(E\left[B_{s}\right]-E\left[Q_{s}\right]\right)$.

The efficient monitoring level satisfies the first order condition:

$$
c^{\prime}\left(m^{F B}\right)=\left(E\left[B_{s}\right]-E\left[Q_{s}\right]\right) x
$$

When considering their choice of $d_{0}$ and $m$ at $t=0$, bank owners anticipate that, for each possible $d_{0}$, if $x_{1}=x$ at $t=1$, the authority will set the optimal intervention policy given such $x$. Such optimal intervention policies can be found by simply replacing $1-\gamma$ with $d_{0}$ in the expression for the optimal public transfer in (18), since Proposition 1 has been derived for $d_{0}=1-\gamma$ but is valid for any $d_{0}$.

Since optimal policies induce full investment at the interim date and make the bank solvent in the two states at $t=2$, we can write the initial net value of the bank to its owners as a function of $d_{0}$ and $m$ as:

$$
\begin{aligned}
\Pi_{0}\left(d_{0}, m\right)= & -\left(1-d_{0}\right)-c(m)+m\left(E\left[B_{s}\right]+\left(E\left[B_{s}\right]-1\right) y-d_{0}\right)+ \\
& +(1-m)\left(E\left[Q_{s}\right] x+E\left[B_{s}\right](1-x)+\left(E\left[B_{s}\right]-1\right) y-d_{0}\right)^{+}
\end{aligned}
$$

The intuition for the net value expression is as follows. The first two terms capture the initial equity contribution by the bank owners and the disutility cost from monitoring loans, respectively. The third and fourth terms are owners' net continuation value at 
$t=1$ conditional on $x_{1}=0$ and $x_{1}=x$, respectively. The fourth term also captures that if the optimal intervention policy features a positive transfer (which happens when $\left.d_{0}>E\left[Q_{s}\right] x+E\left[B_{s}\right](1-x)+\left(E\left[B_{s}\right]-1\right) y\right)$ then the net continuation value of the bank for its owners is zero.

From (33), the bank's optimal monitoring level under a given choice of $d_{0}, m^{*}\left(d_{0}\right)$, satisfies the following first order condition:

$$
c^{\prime}\left(m^{*}\left(d_{0}\right)\right)=\min \left(\left(E\left[B_{s}\right]-E\left[Q_{s}\right]\right) x, E\left[B_{s}\right]+\left(E\left[B_{s}\right]-1\right) y-d_{0}\right),
$$

whose comparison with (32) implies that

$$
m^{*}\left(d_{0}\right)<m^{F B} \text { iff } d_{0}>\bar{d}=E\left[Q_{s}\right] x+E\left[B_{s}\right](1-x)+\left(E\left[B_{s}\right]-1\right) y .
$$

We have thus that monitoring gets reduced relative to its efficient level when the bank's initial deposits are sufficiently large. ${ }^{35}$ The reason is that for $d_{0}>\bar{d}$, the optimal intervention policy under $x_{1}=x$ involves a positive transfer to bank owners.

Since the bank chooses $d_{0}$ at $t=0$ in order to maximize $\Pi_{0}\left(d_{0}, m^{*}\left(d_{0}\right)\right)$, the envelope theorem implies

$\frac{\mathrm{d} \Pi_{0}\left(d_{0}, m^{*}\left(d_{0}\right)\right)}{\mathrm{d} d_{0}}=\left\{\begin{array}{ll}0 & \text { if } d_{0}<E\left[Q_{s}\right] x+E\left[B_{s}\right](1-x)+\left(E\left[B_{s}\right]-1\right) y \\ 1-m^{*}\left(d_{0}\right) & \text { if } E\left[Q_{s}\right] x+E\left[B_{s}\right](1-x)+\left(E\left[B_{s}\right]-1\right) y<d_{0} \leq 1-\gamma\end{array}\right.$.

Thus, for low $d_{0}$, marginal changes in $d_{0}$ do not affect the net value of the bank for its owners. In contrast, for high $d_{0}$, a marginal increase in $d_{0}$ rises one by one the subsidy that bank owners receive from the DGS when $x_{1}=x$ and, thus, increases the continuation value that they extract from the bank in proportion to the probability $1-m^{*}\left(d_{0}\right)$ of such outcome. If $\gamma<1-\bar{d}$, maximizing such subsidy pushes the bank to optimally choose $d_{0}=1-\gamma$ and, subsequently, $m=m^{*}(1-\gamma)<m^{F B}$ (by (35)).

Prior arguments might suggest that the transfers involved in optimal intervention policies are the cause of the inefficiently low monitoring, but this is not the case. To see this, suppose the authority liquidates a bank whenever $T^{*}>0$ and suppose that the bank anticipates at $t=0$ this new intervention rule. Since by design $T^{*}>0$ is just enough to avoid the bank liquidation and leaves a zero net continuation value to the bank owners when $x_{1}=x$, the initial net value of the bank to its owners as a function of $d_{0}$ and $m$ under the new intervention rule would still be given by (33). Hence neither the bank's optimal capital structure nor its monitoring choice would be changed. ${ }^{36}$

\footnotetext{
${ }^{35}$ Under Assumption 4, there exist $d_{0} \leq 1-\gamma$ satisfying the necessary and sufficient condition for inefficient monitoring in (35).

${ }^{36}$ The moral hazard problem that leads to having $m=m^{*}(1-\gamma)<m^{F B}$ in this context is therefore not caused by the intervention with which the authority solves the NPL problem ex post. In fact, for a given value of $d_{0}>\bar{d}$, it is not even caused by the presence of a guarantee on bank deposits but by the unobservability of the monitoring decision $m$. Yet the guarantee on bank deposits explains why the bank chooses $d_{0}=1-\gamma>\bar{d}$ in the first place. If deposits were uninsured and priced according to the choice of $m$ implied by $m^{*}\left(d_{0}\right)$, the bank owners would choose $d_{0} \leq \bar{d}$ and this would lead to $m=m^{F B}$.
} 
Besides, if the authority does not intervene (that is, sets $\alpha=T=0$ ), although still liquidates the bank if it does not comply with capital regulation at $t=1$, bank owners might obtain rents at the expense of the DGS by not undertaking new lending at that date. When that is the case, monitoring incentives get further reduced. The overall conclusion is that, in absence of intervention, the monitoring level can be strictly lower (and is never higher) than under the optimal intervention policies described in the paper.

The next result formalizes our discussion above:

Proposition 2 (Initial capital structure and monitoring decisions) Under the expectation of an optimal intervention at the interim date, bank owners choose as much initial deposits $d_{0}$ as compatible with regulation, $d_{0}=1-\gamma$, and an inefficiently low monitoring level, $m^{*}<m^{F B}$. Liquidating the bank whenever the optimal intervention policy includes positive transfers would not modify these decisions. In contrast, not intervening at the interim date might reduce (and will never increase) the monitoring level.

Proof Only the last statement in the proposition has not been proven in the main text preceding it. Consider a situation in which the authority does not intervene, that is where $\alpha=0, T=0$. The initial net value of the bank to its owners as a function of $d_{0}$ and $m$ can be written as the following expression which is analogous to that in (33):

$$
\begin{aligned}
\widehat{\Pi}_{0}\left(d_{0}, m\right)= & -\left(1-d_{0}\right)-c(m)+m\left(E\left[B_{s}\right]+\left(E\left[B_{s}\right]-1\right) y-d_{0}\right)+ \\
& +(1-m)\left(E\left[Q_{s}\right] x+E\left[B_{s}\right](1-x)+\max \left(\left(E\left[B_{s}\right]-1\right) y, G(0,0 \mid x)\right)-d_{0}\right)(36)
\end{aligned}
$$

where $G(0,0 \mid x)$ denotes the expected value of the guarantee on deposits if the bank is compliant and does not invest and whose expression is given in Lemma 2. The last term takes into account that when $x_{1}=x$, a compliant bank finds optimal to undertake new lending only if $\left(E\left[B_{s}\right]-1\right) y>G(0,0 \mid x)$ and that in such a case the bank is solvent in the two states at $t=2$. That term also captures that the bank owners have the option not to be compliant, let the bank be liquidated and obtain zero value.

For a given $d_{0}$, we have that the bank's optimal monitoring level, $\widehat{m}^{*}\left(d_{0}\right)$, is given by:

$$
c^{\prime}\left(\widehat{m}^{*}\left(d_{0}\right)\right)=\min \left(\left(E\left[B_{s}\right]-E\left[Q_{s}\right]\right) x-\left(G(0,0 \mid x)-\left(E\left[B_{s}\right]-1\right) y\right)^{+}, E\left[B_{s}\right]+\left(E\left[B_{s}\right]-1\right) y-d_{0}\right) .
$$

Comparing with (34) we have that $\widehat{m}^{*}\left(d_{0}\right) \leq m^{*}\left(d_{0}\right)$ for all $d_{0}$ and

$$
\widehat{m}^{*}\left(d_{0}\right)<m^{*}\left(d_{0}\right) \text { iff } G(0,0 \mid x)>\left(E\left[B_{s}\right]-1\right) y \text { and } d_{0}<x E\left[Q_{s}\right]+(1-x) E\left[B_{s}\right]+G(0,0 \mid x) \text {. }
$$

Using the envelope theorem we have that

$$
\frac{\mathrm{d} \widehat{\Pi}_{0}\left(d_{0}, \widehat{m}^{*}\left(d_{0}\right)\right)}{\mathrm{d} d_{0}}=\left\{\begin{array}{ll}
0 & \text { if } d_{0}<E\left[Q_{s}\right] x+E\left[B_{s}\right](1-x)+\max \left(\left(E\left[B_{s}\right]-1\right) y, G(0,0 \mid x)\right) \\
1-m^{*}\left(d_{0}\right) & \text { if } E\left[Q_{s}\right] x+E\left[B_{s}\right](1-x)+\max \left(\left(E\left[B_{s}\right]-1\right) y, G(0,0 \mid x)\right)<d_{0}
\end{array},\right.
$$


Recall that $x$ satisfies Assumption 4. Let us distinguish two cases:

i) $1-\gamma \leq E\left[Q_{s}\right] x+E\left[B_{s}\right](1-x)+G(0,0 \mid x)$

The inequality and Assumption 4 imply that $\left(E\left[B_{s}\right]-1\right) y<G(0,0 \mid x)$. We will show later that there exist $x, y$ such that $i$ ) and Assumption 4 can be satisfied, but for the time being let us assume that for some given $x, y$ the two hold. Then (39) implies that $\frac{\mathrm{d} \widehat{\Pi}_{0}\left(d_{0}, \widehat{m}^{*}\left(d_{0}\right)\right)}{\mathrm{d} d_{0}}=0$ for all $d_{0} \leq 1-\gamma$ and $d_{0}$ is undetermined. Yet, from (34) and (37) we have for any $d_{0}$ that

$$
\begin{aligned}
c^{\prime}\left(\widehat{m}^{*}\left(d_{0}\right)\right) & =\left(E\left[B_{s}\right]-E\left[Q_{s}\right]\right) x+\left(E\left[B_{s}\right]-1\right) y-G(0,0 \mid x)<E\left[B_{s}\right]+\left(E\left[B_{s}\right]-1\right) y-(1-\gamma)= \\
& =\min \left(\left(E\left[B_{s}\right]-E\left[Q_{s}\right]\right) x, E\left[B_{s}\right]+\left(E\left[B_{s}\right]-1\right) y-(1-\gamma)\right)=c^{\prime}\left(m^{*}(1-\gamma)\right),
\end{aligned}
$$

and thus $\widehat{m}^{*}\left(d_{0}\right)<m^{*}(1-\gamma)$.

ii) $1-\gamma>E\left[Q_{s}\right] x+E\left[B_{s}\right](1-x)+G(0,0 \mid x)$

Then (39) implies that $\frac{\mathrm{d} \widehat{\Pi}_{0}\left(d_{0}, \widehat{m}^{*}\left(d_{0}\right)\right)}{\mathrm{d} d_{0}}>0$ for $d_{0}$ sufficiently close to $1-\gamma$ and the bank finds optimal to choose $d_{0}=1-\gamma$. Besides, from (34) and (37) we have that $\widehat{m}^{*}(1-\gamma)=m^{*}(1-\gamma)$.

We have thus far proven that a no intervention policy never increases loan monitoring relative to that induced by the optimal intervention policies described in the baseline model. The only remaining thing to prove is that for some values of the parameters loan monitoring strictly decreases when there are no interventions. In order to prove that, it suffices to show that for $\phi$ sufficiently close to $\gamma$ there exist pairs $x, y$ such that Assumption 4 and condition i) above are satisfied.

Suppose $\phi$ is very close to $\gamma$. From Assumption 1 , we have that $E\left[Q_{s}\right]<1-\gamma<E\left[B_{s}\right]$ which implies that there exists $x^{\prime} \in(0,1)$ such that

$$
E\left[Q_{s}\right] x^{\prime}+E\left[B_{s}\right]\left(1-x^{\prime}\right)=1-\gamma
$$

Since $\phi$ is very close to $\gamma$ the deposits $d_{1}$ at $t=1$ of a compliant bank with a fraction $x^{\prime}$ of NPLs that does not undertake new lending opportunities satisfy $d_{1} \simeq 1-\gamma$. We must necessarily have from (40) that $G\left(0,0 \mid x^{\prime}\right)>0$ because the expected payoff of the bank loans equals the notional value of its deposits and bank loans are risky. Hence using the continuity of the function $G(0,0 \mid x)$, we have that for $x$ slightly below $x^{\prime}$ the following inequality is satisfied

$$
E\left[Q_{s}\right] x+E\left[B_{s}\right](1-x)<1-\gamma<E\left[Q_{s}\right] x+E\left[B_{s}\right](1-x)+G(0,0 \mid x) .
$$

Choosing $y$ low enough we obtain a pair $x, y$ that satisfies Assumption 4 and condition $i$ ).

\section{B.2 Asymmetric information on NPLs}

Suppose the bank has private information on the measure $x \in[0,1]$ of NPLs with which it arrives at $t=1$. In order to extract the bank's private information, the authority can set a menu of intervention policies $\left(\alpha_{\widehat{x}}, T_{\widehat{x}}\right)_{\widehat{x} \in[0,1]}$ that specifies the intervention policy for each 
possible amount of NPLs $\widehat{x}$ declared by the bank. By virtue of the Revelation Principle we can focus on truth-revealing menus, that is, menus that induce a bank with a fraction $x$ of NPLs to declare $\widehat{x}=x$ and thus be applied the intervention policy $\left(\alpha_{x}, T_{x}\right)$.

Recall that for each possible value of $x$, the optimal intervention policies with symmetric information are described in Proposition 1. For each $x$, let us denote the transfer common to all optimal policies by $T^{*}(x)$ so that $\left(1, T^{*}(x)\right)$ is the optimal policy with a requirement to dispose of all the NPLs.

Let us now address whether the menu $\left(1, T^{*}(x)\right)_{x}$ induces the bank to reveal its "type" for all values of $x$. Let us denote $\bar{x}$ the maximum $x$ for which $T^{*}(x)=0$. Using (18), $\bar{x}$ is given by

$$
1-\gamma=E\left[Q_{s}\right] \bar{x}+E\left[B_{s}\right](1-\bar{x})+\left(E\left[B_{s}\right]-1\right) y .
$$

To analyze the incentives of the bank to misreport $x$, consider sequentially the possibility of overstating and understating the fraction of NPLs. First, if the bank reports some $x^{\prime}>x$ then the authority asks it to dispose of a fraction $x^{\prime}$ of loans at the NPL market price $q=E\left[Q_{s}\right]$ and provides a transfer $T\left(x^{\prime}\right) \cdot{ }^{37}$ Since $q<E\left[B_{s}\right]$, the best possible deviation of this class would involve selling all the NPLs and also an amount $x^{\prime}-x$ of performing loans, on which the bank would make a loss amounting to $\left(E\left[B_{s}\right]-E\left[Q_{s}\right]\right)\left(x^{\prime}-x\right)>0$. By reporting $x^{\prime}$, the bank may enjoy a higher transfer $T\left(x^{\prime}\right)$ but, from (18), we have that $T\left(x^{\prime}\right)-T(x) \leq\left(E\left[B_{s}\right]-E\left[Q_{s}\right]\right)\left(x^{\prime}-x\right)$, so overstating the amount of NPLs is not profitable.

Next, suppose the bank reports some $x^{\prime}<x$. There are two effects on the net value of the bank to its owners. First, after disposing of a fraction $x^{\prime}$ of loans, which the bank would find optimal to select from its pool of NPLs, the bank would retain a measure $x^{\prime}-x$ of NPLs. Yet, the regulatory environment would impose a capital requirement $\gamma$ on those loans (presuming they are performing loans) so the bank may enjoy some subsidy from the DGS. Second, understating the fraction of NPLs by reporting $x^{\prime}<x$ reduces by $T(x)-T\left(x^{\prime}\right)$ the transfer received from the authority. ${ }^{38}$

The higher the fraction of NPLs, the more likely the bank is to benefit from a positive subsidy (and hence the higher its incentives to under-report). We thus have that a bank with NPLs amounting to the threshold $\bar{x}$ that reports to have no NPLs would find itself in the best position to benefit from under-reporting. In fact, a sufficient condition for such deviation to be profitable is that, conditional on undertaking the new lending in full, the bank is not solvent in the two states, as this would provide bank owners with a subsidy which would disappear under truthful reporting. The condition for insolvency in state $L$ can

\footnotetext{
${ }^{37}$ This design prevents the bank from selling good loans at a price different from $q$. In practice, this may require the loans to be sold to an instrumental AMC under the control of the authority so as to rule out the possibility of selling good loans (say, to agents privately informed about their quality) at prices higher than $q$ and hiding the excess price achieved in such sale.

${ }^{38}$ If the measure of NPLs with which the bank arrives at $t=1$ is not above the threshold $\bar{x}$, then $T(x)=T\left(x^{\prime}\right)=0$ and this negative effect will not arise.
} 
be written as

$$
(1-\gamma)(1+y)>Q_{L} \bar{x}+B_{L}(1-\bar{x}+y)
$$

where the LHS contains the maximum amount of deposits that a bank with a measure $1+y$ of performing loans would be allowed to take, and the RHS is the return in state $L$ of a bank that keeps its measure $\bar{x}$ of NPLs and undertakes its new lending in full. For low values of $y$, the definition of $\bar{x}$ in (41) implies that inequality (42) is satisfied. ${ }^{39}$ Therefore, in some cases the bank may have incentives to under-report its NPLs and the initially proposed menu of intervention policies is not incentive compatible.

In those cases, the authority can remove the under-reporting incentives (without otherwise affecting the cost or effectiveness of the proposed intervention) by setting a sufficiently large capital requirement $\gamma^{\prime}$ on loans held after $t=1$. The goal would be to ensure that an under-reporting bank does not benefit from additional deposit-based subsidies. Notice that, under our assumptions, the increase in the capital requirement has no cost to bank owners if the bank reports its true fraction of NPLs (or a higher one) since in that case the original requirement was already sufficient to ensure that, after the disposal of its NPLs, the bank was solvent in the two states.

The above discussion can be extended to banks with a NPL fraction $x \neq \bar{x}$ and the next formal result can be proven.

Proposition 3 (Optimal intervention with asymmetric information) If the initial measure of NPLs at $t=1$ is bank owners' private information, implementing an optimal intervention requires in some cases to increase the capital requirement on the loans held after $t=1$. Specifically, the policy menu $\left(1, T^{*}(x)\right)_{x}$ and a capital requirement $\gamma^{\prime} \geq \gamma$ on loans held after $t=1$ induces each bank to truthfully reveal (dispose of) its NPL if and only if

$$
\left(E\left[B_{s}\right]-1\right) y \geq E\left[\left(1-\gamma^{\prime}-Q_{s} \bar{x}-B_{s}(1-\bar{x})\right)^{+}\right],
$$

where $\bar{x}$ is the maximum $x$ such that $T^{*}(x)=0$. Moreover, $\gamma^{\prime}>\gamma$ if $y$ is sufficiently low.

Proof Consider the menu of intervention policies $\left(1, T^{*}(x)\right)_{x}$ and a capital requirement per unit of loans retained at $t=1$ equal to $\gamma^{\prime} \geq \gamma$ and satisfying (43). Let $\bar{x}$ be given by (41). Let us refer to the measure $x$ of NPLs initially held by the bank at $t=1$ as the bank's type. Notice that the intervention policies in the menu above induce a truth-reporting bank to be compliant. Misreporting is a strictly optimal deviation for a bank type only if it implies a strictly positive net continuation value for bank owners, which requires in particular the bank to be compliant. Hence, in order to consider the bank's incentives to misreport their type we can assume that a misreporting bank is compliant.

\footnotetext{
${ }^{39}$ Intuitively, the threshold $\bar{x}$ in (41) defines the maximum fraction of NPLs such that the bank's expected net worth under the capital requirement $\gamma$ is just zero, which implies that the bank is not solvent in state $L$.
} 
Consider a bank of type $x$, and let $\Pi\left(x^{\prime}, I \mid x\right)$ denote owners' net value if the bank chooses the intervention designed for type $x^{\prime}$ and subsequently (complies and) undertakes new lending I. Also, let $G\left(x^{\prime}, I \mid x\right)$ be the cost of the bank to the DGS under such choice. We have:

$$
\begin{aligned}
G\left(x^{\prime}, I \mid x\right)= & \begin{cases}E\left[\left(\left(1-\gamma^{\prime}\right)\left(1-x^{\prime}+I\right)-Q_{s}\left(x-x^{\prime}\right)-B_{s}(1-x+I)\right)^{+}\right], & \text {if } x^{\prime}<x, \\
0, & \text { if } x^{\prime} \geq x,\end{cases} \\
\Pi\left(x^{\prime}, I \mid x\right)= & E\left[Q_{s}\right] x+E\left[B_{s}\right](1-x)-(1-\gamma)+T\left(x^{\prime}\right) \\
& -\left(E\left[B_{s}\right]-E\left[Q_{s}\right]\right)\left(x^{\prime}-x\right)^{+}+\left(E\left[B_{s}\right]-1\right) I+G\left(x^{\prime}, I \mid x\right)
\end{aligned}
$$

The expression for $G\left(x^{\prime}, I \mid x\right)$ is derived using two observations. On the one hand, if $x^{\prime}<x$ the bank is allowed to issue $\left(1-\gamma^{\prime}\right)\left(1-x^{\prime}+I\right)$ units of deposits and keeps $x-x^{\prime}$ units of NPLs. Notice that it could be the case that an under-reporting bank is insolvent in the two states. On the other hand, $G\left(x^{\prime}, I \mid x, \gamma^{\prime}\right)=0$ if $x^{\prime} \geq x$ because the bank in that case only keeps performing loans, and these loans have a capital excess in state $L .{ }^{40}$ In the expression for $\Pi\left(x^{\prime}, I \mid x\right)$, the first three terms capture the value of assets minus the deposit obligations with which the bank enters $t=1$. The fourth term includes the transfer obtained by reporting $x^{\prime}$. The fifth term reflects the losses associated with selling performing loans at the NPL loan market price if the bank overstates its NPLs. The sixth term is the NPV generated by the new lending, and the last term is the subsidy associated with the deposits kept after reporting NPLs of size $x^{\prime}$.

We derive next some properties and results that will be useful in the rest of the proof:

i) For $x^{\prime}<x$ we have

$$
\frac{\partial \Pi\left(x^{\prime}, I \mid x\right)}{\partial I}=E\left[B_{s}\right]-1- \begin{cases}E\left[B_{s}\right]-1+\gamma^{\prime}, & \text { if }\left(1-\gamma^{\prime}\right)\left(1-x^{\prime}+I\right) \geq Q_{H}\left(x-x^{\prime}\right)+B_{H}(1-x+I), \\ 0, & \text { if }\left(1-\gamma^{\prime}\right)\left(1-x^{\prime}+I\right)<Q_{L}\left(x-x^{\prime}\right)+B_{L}(1-x+I), \\ (1-\mu)\left(B_{L}-1+\gamma^{\prime}\right), & \text { otherwise. }\end{cases}
$$

Using that $\gamma^{\prime} \geq \gamma$ and Assumption 3 we have that

$$
\frac{\partial \Pi\left(x^{\prime}, I \mid x\right)}{\partial I}>0 \text { iff }\left(1-\gamma^{\prime}\right)\left(1-x^{\prime}+I\right)<Q_{L}\left(x-x^{\prime}\right)+B_{L}(1-x+I),
$$

which implies in particular that, as in the baseline model, if bank owners find optimal to undertake the new lending then, conditional on doing so, the bank is solvent in the two states, and bank owners find it optimal to undertake the new lending if and only if

$$
\left(E\left[B_{s}\right]-1\right) y \geq G\left(x^{\prime}, 0 \mid x\right) .
$$

ii) For $x^{\prime}<x$ we have

$$
\frac{\partial G\left(x^{\prime}, I \mid x\right)}{\partial x^{\prime}}= \begin{cases}E\left[Q_{s}\right]-1+\gamma^{\prime}, & \text { if }\left(1-\gamma^{\prime}\right)\left(1-x^{\prime}+I\right) \geq Q_{H}\left(x-x^{\prime}\right)+B_{H}(1-x+I), \\ 0, & \text { if }\left(1-\gamma^{\prime}\right)\left(1-x^{\prime}+I\right)<Q_{L}\left(x-x^{\prime}\right)+B_{L}(1-x+I), \\ (1-\mu)\left(Q_{L}-1+\gamma^{\prime}\right), & \text { otherwise. }\end{cases}
$$

\footnotetext{
${ }^{40}$ The excess capital on performing loans implies in addition that there exists $\varepsilon>0$ such that $G\left(x^{\prime}, I \mid x, \gamma^{\prime}\right)=0$ if $x^{\prime} \in(x-\varepsilon, x)$.
} 
This expression in (48), Assumption 1, and Assumption 2 imply in particular (after some case-by-case straightforward algebra) that

$$
-\left(E\left[B_{s}\right]-E\left[Q_{s}\right]\right)<\frac{\partial G\left(x^{\prime}, I \mid x, \gamma^{\prime}\right)}{\partial x^{\prime}} \leq 0
$$

iii) For $x^{\prime}<x$ we have

$$
\frac{\partial G\left(x^{\prime}, 0 \mid x\right)}{\partial x}= \begin{cases}E\left[B_{s}\right]-E\left[Q_{s}\right], & \text { if }\left(1-\gamma^{\prime}\right)\left(1-x^{\prime}+I\right) \geq Q_{H}\left(x-x^{\prime}\right)+B_{H}(1-x+I), \\ 0, & \text { if }\left(1-\gamma^{\prime}\right)\left(1-x^{\prime}+I\right)<Q_{L}\left(x-x^{\prime}\right)+B_{L}(1-x+I), \\ (1-\mu)\left(B_{H}-Q_{H}\right), & \text { otherwise. }\end{cases}
$$

This expression in particular implies that

$$
\frac{\partial G\left(x^{\prime}, 0 \mid x\right)}{\partial x} \geq 0
$$

iv) For any $x$ we have

$$
\frac{d T\left(x^{\prime}\right)}{d x^{\prime}}= \begin{cases}E\left[B_{s}\right]-E\left[Q_{s}\right], & \text { if } x^{\prime} \geq \bar{x} \\ 0, & \text { otherwise }\end{cases}
$$

We can now show that bank owners will have no incentives to deviate from the truthful reporting of their NPLs for any $x$. In the main text before the proposition we have proved that no bank has incentives to overstate its type (that is, to report $x^{\prime}>x$ ), so it suffices to focus now on under-reporting.

Let us denote $\Pi\left(x^{\prime} \mid x\right)=\max \left(\Pi\left(x^{\prime}, y \mid x\right), \Pi\left(x^{\prime}, 0 \mid x\right)\right)$. We want to prove that

$$
\Pi\left(x^{\prime} \mid x\right) \leq \Pi(x \mid x) \text { for all } x \text { and } x^{\prime}<x .
$$

Let us distinguish two cases:

a) $x \leq \bar{x}$. Suppose that $x^{\prime}<x$, then using (49) and (52) we have that it suffices to focus on $x^{\prime}=0$ and to prove that $\Pi(0 \mid x) \leq \Pi(x \mid x)$.

We have

$$
\left(E\left[B_{s}\right]-1\right) y \geq E\left[\left(1-\gamma^{\prime}-Q_{s} \bar{x}-B_{s}(1-\bar{x})\right)^{+}\right]=G(0,0 \mid \bar{x}) \geq G(0,0 \mid x),
$$

where the first inequality is (43), the second equality stems from (44), and the last inequality relies on $x \leq \bar{x}$ and (51). Looking at the extremes of the inequality above we deduce that (47) is satisfied for $x^{\prime}=0$ and the misreporting bank finds optimal to undertake its new lending in full. This in particular implies that after doing so the bank is solvent in the two states, that is $G(0, y \mid x)$. Taking into account that a bank that truthfully reports its type does not enjoy deposit insurance subsidies, and lends in full, that is $G(x, y \mid x)=0$, we conclude that $\Pi(0 \mid x)=\Pi(x \mid x)$. 
b) $x>\bar{x}$. Suppose first that $x^{\prime} \geq \bar{x}$. Then, using (49), (52) and the definition of $\Pi\left(x^{\prime} \mid x\right)$, we have from (45) that

$$
\begin{aligned}
\frac{\partial \Pi\left(x^{\prime} \mid x\right)}{\partial x^{\prime}} & \geq \min \left(\frac{\partial G\left(x^{\prime}, y \mid x\right)}{\partial x^{\prime}}, \frac{\partial G\left(x^{\prime}, 0 \mid x\right)}{\partial x^{\prime}}\right)+\frac{d T\left(x^{\prime}\right)}{d x^{\prime}} \\
& >-\left(E\left[B_{s}\right]-E\left[Q_{s}\right]\right)+\frac{d T\left(x^{\prime}\right)}{d x^{\prime}}=0,
\end{aligned}
$$

so that $\Pi\left(x^{\prime} \mid x\right)<\Pi(x \mid x)$.

Suppose next that $x^{\prime}<\bar{x}$. Then, using (49) and (52), we have again that it suffices to focus on $x^{\prime}=0$ and prove that $\Pi(0 \mid x) \leq \Pi(x \mid x)$. From (45), (50), (52) and the definition of $\Pi\left(x^{\prime} \mid x\right)$, we have that

$$
\begin{aligned}
\frac{\partial(\Pi(0 \mid x)-\Pi(x \mid x))}{\partial x} & \leq \max \left(\frac{\partial G(0, y \mid x)}{\partial x}, \frac{\partial G(0,0 \mid x)}{\partial x}\right)-\frac{d T(x)}{d x} \\
& \leq E\left[B_{s}\right]-E\left[Q_{s}\right]-\frac{d T(x)}{d x}=0 .
\end{aligned}
$$

We have proved in a) that $\Pi(0 \mid \bar{x})=\Pi(\bar{x} \mid \bar{x})$, and thus the inequality above implies $\Pi(0 \mid x) \leq \Pi(x \mid x)$ for all $x>\bar{x}$.

To conclude the proof we have to show that the condition (43) on $\gamma^{\prime}$ is necessary for $\left(1, T^{*}(x)\right)_{x}$ to induce truth-telling. Suppose (43) is not satisfied. Then (47) implies that if the owners of the bank of type $\bar{x}$ report $x^{\prime}=0$ then they would find strictly optimal not to undertake any new lending. As a result, using (45) we have that

$$
\begin{aligned}
\Pi(0 \mid \bar{x}) & =\Pi(0,0 \mid x)>\Pi(0, y \mid x) \\
& =E\left[Q_{s}\right] x+E\left[B_{s}\right](1-x)-(1-\gamma)+\left(E\left[B_{s}\right]-1\right) y+G(0, y \mid x) \\
& \geq E\left[Q_{s}\right] x+E\left[B_{s}\right](1-x)-(1-\gamma)+\left(E\left[B_{s}\right]-1\right) y=\Pi(\bar{x} \mid \bar{x}),
\end{aligned}
$$

so that the owners of the bank of type $\bar{x}$ would have incentives to misreport its NPLs.

\section{B.3 Risk-shifting in new lending opportunities}

The focus of the baseline model is on the optimal policies to deal with the legacy problems of a bank with new profitable lending opportunities. Yet, one of the concerns when dealing with banks in distress is their incentive to gamble, that is, to undertake risky investments with the purpose of benefiting from risk shifting. In this section we show that the main results of the paper remain valid when the bank has a risk-shifting opportunity provided the authority rises the NPL disposal requirement enough to remove bank owners' gambling temptation.

In the baseline model the bank at $t=1$ has the opportunity to undertake up to $y$ units of lending with a payoff structure equal to that of performing loans. We refer to this positive 
NPV investment as "good lending." We now assume that, as an alternative, the bank could undertake up to $y$ units of "risky lending" with return $\widetilde{B}_{s}$ in state $s$, where $\widetilde{B}_{L}<B_{L}$, $\widetilde{B}_{H}>B_{H}$, and $E\left[\widetilde{B}_{s}\right]<E\left[B_{s}\right]$.

To streamline the presentation, consider the polar case with $\widetilde{B}_{L}=0$ and $\widetilde{B}_{H}$ that satisfies:

Assumption $61<\mu \widetilde{B}_{H}+(1-\mu)(1-\gamma)<E\left[B_{s}\right]$.

The precise implications of this assumption will become clear below but it essentially requires that the expected payoff of the risk-shifting opportunity is sufficiently lower than that of good lending but not too low. The authority is assumed to observe the amount of new lending $I$ but not bank owners' choice between good and risky lending. Finally, the capital requirement per unit of new lending remains $\gamma$.

Suppose that a bank newly created at $t=1$ could decide between the two lending opportunities subject to the per unit capital requirement $\gamma$. From Assumption 1, bank owners' expected net present value per unit of lending for each of the lending opportunities would be

$$
\begin{array}{ll}
\text { Good lending: } & E\left[B_{s}\right]-1 . \\
\text { Risk-shifting: } & \mu \widetilde{B}_{H}+(1-\mu)(1-\gamma)-1 .
\end{array}
$$

Notice that the value of risky lending to bank owners includes the expected payoff of the investment, $\mu \widetilde{B}_{H}$, and the expected value of its associated deposit guarantees, $(1-\mu)(1-\gamma)$. Yet, Assumption 6 implies that a "newly" created bank would strictly prefer good lending to risky lending, and risky lending to no lending at all. A bank without legacy assets would thus maximize the overall value of its investments and cause no costs to the authority. As we show next this is not the case in the presence of legacy problems.

Consider a bank with a fraction $x$ of NPLs and the two competing lending opportunities with an overall maximum size $y$. Since the expected payoff of good lending is higher than that of risky lending, the sufficient optimality condition in Lemma 1 can be adapted to this setting by replacing new lending with new good lending. Suppose the authority sets an intervention policy $(\alpha, T)$. To analyze the bank's compliance and new lending decision, denote by $\widetilde{G}(\alpha, I \mid x)$ and $\widetilde{\Pi}(\alpha, T, I \mid x)$ the expected cost of the bank to the DGS and the net value of the bank to its owners if the bank is compliant an undertakes $I$ units of risky lending. The expressions for these variables, which are analogous to those in (11) and (12), are given by:

$$
\begin{aligned}
\widetilde{G}(\alpha, I \mid x) & \left.=(1-\mu)\left[\left(\delta_{B}-(1-\alpha) \delta_{Q}\right) x-\delta_{B}+(1-\gamma) I\right)\right]^{+} \\
\widetilde{\Pi}(\alpha, T, I \mid x) & =E\left[Q_{s}\right] x+E\left[B_{s}\right](1-x)-(1-\gamma)+\left(\mu \widetilde{B}_{H}-1\right) I+\widetilde{G}(\alpha, I \mid x)+T .
\end{aligned}
$$

Notice that the term $(1-\gamma) I$ in the expression for $\widetilde{G}(\alpha, I \mid x)$ accounts for the expected subsidy per unit of risky lending received from the DGS in state $L$. The analogous term in $\widetilde{G}(\alpha, I \mid x)$ was $-\delta_{B} I<0$, and accounted for the fact that new good lending reduces the 
expected subsidy from the DGS, which was the reason why the bank might find optimal not to undertake good lending in the baseline model.

From (54), (55) and Assumption 6 we have that

$$
\frac{\partial \widetilde{\Pi}(\alpha, T, I \mid x)}{\partial I} \geq \mu \widetilde{B}_{H}-1-(1-\mu)(1-\gamma)>0,
$$

which means that a compliant bank will never pass up the opportunity to lend because such option is dominated by the full undertaking of risky lending. Hence, an intervention policy induces a compliant bank to undertake good lending if and only if it makes it preferable to risky lending. We next show that that is not always the case under the minimal optimal policies of the baseline model.

In fact, let $x, y$ be such that $\alpha_{\text {lend }}(x, y)>0$. By the definition of $\alpha_{\text {lend }}(x, y)$ in Lemma 3 and using (56) we have that:

$$
\widetilde{\Pi}\left(\alpha_{\text {lend }}(x, y), T, y \mid x\right)>\widetilde{\Pi}\left(\alpha_{\text {lend }}(x, y), T, 0 \mid x\right)=\Pi\left(\alpha_{\text {lend }}(x, y), T, 0 \mid x\right)=\Pi\left(\alpha_{\text {lend }}(x, y), T, y \mid x\right),
$$

which means that for an NPL disposal requirement $\alpha_{\text {lend }}(x, y)$ a compliant bank strictly prefers risky lending. This implies that, if $\alpha^{*}>0$, the minimal optimal intervention policies in Proposition 1 do not induce good lending.

Recall that from (53) and the second inequality in Assumption 6 we have that a bank with no legacy portfolio would find strictly optimal to undertake good lending. Using that $\delta_{B}>0$, it is a matter of simple algebra to check that this implies that:

$$
\widetilde{\Pi}(\alpha=1, T, y \mid x)<\Pi(\alpha=1, T, y \mid x) .
$$

The inequality says that a compliant bank that disposes its entire portfolio of NPLs finds strictly optimal to undertake good lending. The intuition is that after the disposal of all the NPLs, the only legacy loans in the bank portfolio are performing ones, which have a capital surplus in state $L$ and, if anything, strengthen bank owners' incentives to undertake good lending relative to those of a bank with no legacy loans.

From (57), (58). and the results in Proposition 1 we obtain that:

Proposition 4 (Optimal policies with risk-shifting possibilities) Let $\left(\alpha^{*}, T^{*}\right)$ be the minimal optimal intervention policy in the baseline model and suppose that the bank has the opportunity to undertake some competing new risky lending. The minimal optimal intervention policy $\left(\widetilde{\alpha}^{*}, \widetilde{T}^{*}\right)$ in this economy satisfies

$$
\begin{aligned}
& \alpha^{*} \leq \widetilde{\alpha}^{*}<1 \text { and } \widetilde{\alpha}^{*}>\alpha^{*} \text { if } \alpha^{*}>0 \\
& \widetilde{T}^{*}=T^{*}
\end{aligned}
$$

and induces the same expected cost to the authority as in the baseline model. 
Proof Results immediately from Lemma 3, Proposition 1, the extended version of the sufficient optimality condition in Lemma 1 for the economy with risk-shifting opportunities, and equations (57) and (58).

The proposition states that, while the presence of risk-shifting opportunities does not increase the cost of the legacy problem to the authority, preventing risk shifting may force the authority to impose a larger NPL disposal requirement than in the baseline setup.

\section{B.4 Purchase and assumption interventions}

The next proposition states formally the results discussed in Section 6.1:

Proposition 5 (Optimal PGA interventions) Let $\left(\alpha^{*}, T^{*}\right)$ be the minimal optimal intervention policy in the baseline model and suppose that there is a strong bank with $z>0$ units of performing loans. The minimal optimal P\&A intervention $\left(\widetilde{\alpha}, \widetilde{T}_{s}, \widetilde{T}_{w}\right)$ satisfies $\widetilde{\alpha} \leq \alpha^{*}$,

with $\widetilde{\alpha}<\alpha^{*}$ if $\alpha^{*}>0, \widetilde{T}_{s}=T^{*}$, and $\widetilde{T}_{w}=0$ if $\widetilde{T}_{s}>0$. Besides, $\widetilde{\alpha}$ is decreasing in $z$, and $\widetilde{\alpha}=0$ if $z$ is sufficiently large.

Proof From (20), the optimality condition analogous to Lemma 1 states that P\&A intervention policy $\left(\alpha, T_{s}, T_{w}\right)$ is optimal if it induces full new lending and, if it involves a positive cost to the authority, then $\Pi_{w}=0$ and $\Pi_{s}=\bar{\Pi}_{s}$. For given $\alpha$ and $I$, from (21) we have that the cost for the DGS of the compliant merged bank is:

$$
\widetilde{G}(\alpha, I \mid x)=(1-\mu)\left(-\delta_{Q}(1-\alpha) x-\delta_{B}(1-x+I+z)\right)^{+}
$$

The minimum NPL disposal requirement inducing full new lending, $\widetilde{\alpha}_{\text {lend }}(x, y, z)$, is given by:

$$
\left(E\left[B_{s}\right]-1\right) y=\widetilde{G}\left(\widetilde{\alpha}_{\text {lend }}(x, y, z), 0 \mid x\right) .
$$

Comparing these expressions to those in (11) and (15), we have that

$$
\begin{aligned}
& \widetilde{\alpha}_{\text {lend }}(x, y, z) \leq \alpha_{\text {lend }}(x, y) \text { and } \\
& \widetilde{\alpha}_{\text {lend }}(x, y, z)<\alpha_{\text {lend }}(x, y) \text { if } \alpha_{\text {lend }}(x, y)>0
\end{aligned}
$$

Moreover, (59) and (60) imply that $\widetilde{\alpha}_{\text {lend }}(x, y, z)$ is decreasing in $z$, and equal to zero if $z$ is sufficiently large. Finally, the expression for $\Pi_{w}$ an be obtained from (20). As in the baseline model, a merged bank that finds optimal to undertake new lending will be solvent in state $L$. The results in the proposition then immediately follow using the same arguments leading to Proposition 1 in Section 5.3. 


\section{B.5 Interventions based on provisioning}

International Accounting Standards (IAS) require banks to provision their NPLs on an expected lifetime basis. In our model such losses amount to $1-q$, which implies that the net carrying value of NPLs, defined as their initial book value minus provisions, amounts to $q .{ }^{41}$ Supervisors may impose prudential adjustments on the level of provisioning based on valuing the NPLs in a more conservative manner, say at a per unit value $q^{\prime} \leq q$, and forcing the bank to deduct the valuation difference of its retained NPLs, $\left(q-q^{\prime}\right)(1-\alpha) x$, from its available regulatory capital. Additionally, depending on the approach to capital requirements under which the bank operates, NPLs may also be subject to capital requirements, say in the form of a requirement $\gamma^{\prime}$ imposed on the gross carrying amount of the retained NPLs, $(1-\alpha) x .^{42}$ With these ingredients, the constraint imposed by provisioning and capital requirements at $t=1$ could be described as follows:

$$
(1-\alpha) x+(1-x)+I-d_{1}-\left(1-q^{\prime}\right)(1-\alpha) x \geq \gamma^{\prime}(1-\alpha) x+\gamma(1-x+I),
$$

where the LHS is the available regulatory capital at $t=1$ (gross book asset value minus deposit liabilities minus provisions) and the RHS is the required regulatory capital (required capital on retained NPLs plus required capital on performing and new loans). This constraint can be rewritten as

$$
(1-\alpha) x+(1-x)+I-d_{1} \geq\left(\left(1-q^{\prime}\right)+\gamma^{\prime}\right)(1-\alpha) x+\gamma(1-x+I)
$$

which for $\phi=\left(1-q^{\prime}\right)+\gamma^{\prime}$ is equivalent to the constraint (8) used in our baseline analysis. This equivalence supports our claim that $\phi$ can be interpreted as capturing the combined effect of provisioning and capital requirements. Notice that under this interpretation the restriction imposed in Assumption 1 holds insofar as $Q_{L}<q^{\prime}-\gamma^{\prime} \leq Q_{H}$, and in particular holds for $q^{\prime}=q$ and $\gamma^{\prime}=0$.

The next proposition states formally the results discussed in Section 6.2:

\footnotetext{
${ }^{41}$ For banks reporting under IAS, the accounting treatment of NPLs has not susbtantially changed with the substitution of IAS 39 standards with IFRS 9 on 1 January 2018.

${ }^{42}$ The capital requirements applied to NPLs vary across the various approaches considered in the Basel agreements. Under the standardised approach (SA), the unsecured portion of loans past due for more than 90 days and with provisions exceeding $20 \%$ of the outstanding amount carry a 100\% risk weight (Basel Committee on Banking Supervision, 2017). The risk weight applies to the net carrying amount and rises to $150 \%$ when the provisions are below the threshold of $20 \%$. The internal ratings-based approach (IRB) is based on the principle that expected losses are covered by provisions and the purpose of required capital is to cover residual unexpected losses. Then, under the advanced IRB, the capital requirement on a defaulted exposure is given by the difference between some estimated adverse-scenario loss-given-default (LGD) and the bank's best estimate of the expected loss, where the latter is supposed to be covered by provisions. Finally, under the foundation IRB (where no modelling of LGDs is involved), all losses on defaulted exposures are treated as expected and hence supposedly covered by the deduction of the expected losses from CET1 capital via provisioning.
} 
Proposition 6 (Substitutability between NPL disposal E prudential provisioning) Let $\phi_{0}$ be the value of the regulatory capital requirement per unit of NPLs implied by accounting standards and capital regulation, and $\left(\alpha^{*}, T^{*}\right)$ the minimal optimal intervention policy of the baseline set-up described in Proposition 1 for the given value $\phi_{0}$. The minimal optimal intervention of the class $(\phi, T)$ with $\phi \geq \phi_{0}$, is $\left(\phi^{*}, T^{*}\right)$ with $\phi^{*}=\left(1-\alpha^{*}\right) \phi_{0}+\alpha^{*}\left(1-Q_{L}\right)$.

Proof The proposition is an immediate consequence of the arguments in Section 6.2 and the comparison between (10) and (22).

\section{B.6 Long-term debt and the need for bail-in arrangements}

The next proposition states formally the results discussed in Section 6.3:

Proposition 7 (Optimal policy with uninsured LT debt) When the bank has outstanding uninsured LT debt and the authority has bail-in powers on it, then optimal intervention policies induce the undertaking of all new profitable lending and impose some bail-in on LT debt whenever they involve public transfers. In contrast, if the authority does not have bail-in powers, in some cases optimal policies do not induce new lending (and could lead to resolution).

Proof Suppose the authority has bail-in powers. The proof of the proposition follows closely the sequence of intermediate results in the baseline model in Section 4 and 5. For the sake of brevity, we only sketch them here highlighting the main differences and new arguments.

Let $\left(\alpha, h_{1}, T\right)$ be an intervention policy compliant with the LT debt bail-in rules. From the expression for the cost of the bank for the authority in $(24)$, we deduce that if $\left(\alpha, h_{1}, T\right)$ satisfies the two following properties then it is an optimal policy. First, it induces full new lending, $I=y$. Second, if it leads to a positive cost to the authority, $C>0$, then bank owners' net continuation value is zero, $\Pi=0$, and the continuation value of LT debt is equal to that under bank resolution, $H=H_{\text {res }}$. In addition, if $\left(\alpha, h_{1}, T\right)$ meets the two criteria then any optimal intervention policy meets them as well.

Given the policy set by the authority, a compliant bank that undertakes new lending $I$ will always find (weakly) optimal to raise as much deposit funding as allowed by the regulatory environment, so that

$$
d_{1}+h_{1}=(1-\phi)(1-\alpha) x+(1-\gamma)(1-x+I)
$$

Comparing to (9) we have that the overall notional amount of the debt issued by the bank coincides with that in the baseline model and in particular is affected by the intervention policy only through $\alpha$. As a result, the intervention policy induces full lending by a compliant 
bank if and only if $\alpha \geq \alpha_{\text {lend }}(x, y)$ and, in that case, the bank is solvent in the two states, so that $H=h_{1}$.

Consider the policy $\left(\alpha^{*}, h_{1}, T\right)$ with $\alpha^{*} \geq \alpha_{\text {lend }}(x, y), h_{1} \leq h_{0}$. Taking into account that the policy induces full lending by a compliant bank and the bank to be solvent in the two states, we have from (24) that the net continuation value for the bank owners under compliance would be:

$$
\Pi\left(\alpha^{*}, h_{1}, T\right)=\left(E\left[B_{s}\right]-1\right) I+\left(E\left[Q_{s}\right] x+E\left[B_{s}\right](1-x)-d_{0}\right)-h_{1}+T .
$$

If $\Pi\left(\alpha^{*}, h_{0}, 0\right) \geq 0$ then the intervention policy $\left(\alpha^{*}, h_{0}, 0\right)$ meets the (extended) optimality conditions so that any optimal policy avoids resolution and leads to full lending. Moreover any other optimal policy $\left(\alpha^{\prime}, h_{1}^{\prime}, T^{\prime}\right)$ must have $h_{1}^{\prime}=h_{0}, T^{\prime}=0$. Otherwise from (64) we would have that $\Pi\left(\alpha^{\prime}, h_{1}^{\prime}, T^{\prime}\right)>0$ and the policy would either not meet the optimality conditions or the LT debt bail-in rules. The proposition is thus satisfied.

Suppose that $\Pi\left(\alpha^{*}, h_{0}, 0\right)<0$ and let us distinguish two cases.

i) $\Pi\left(\alpha^{*}, H_{\mathrm{res}}, 0\right) \geq 0$. In this case, we have that there exists a unique $h_{1}^{*} \in\left[H_{\mathrm{res}}, h_{0}\right]$ such that $\Pi\left(\alpha^{*}, h_{1}^{*}, 0\right)=0$. By construction, the intervention policy satisfies the LT debt bail-in rules, leads to full lending and zero cost for the authority. Then the (extended) optimality conditions imply that $\left(\alpha^{*}, h_{1}^{*}, 0\right)$ is optimal and that any other optimal policy must meet the optimality conditions. From (64) we easily deduce that any other optimal policy $\left(\alpha^{\prime}, h_{1}^{\prime}, T^{\prime}\right)$ must have $h_{1}^{\prime}=h_{1}^{*}, T^{\prime}=0$, and the proposition is satisfied.

ii) $\Pi\left(\alpha^{*}, H_{\mathrm{res}}, 0\right)<0$. Let us define $h_{1}^{*}=H_{\mathrm{res}}, T^{*}=-\Pi\left(\alpha^{*}, H_{\mathrm{res}}, 0\right)>0$. Then by construction the intervention policy $\left(\alpha^{*}, h_{1}^{*}, T^{*}\right)$ meets the LT debt bail-in rules and the (extended) optimality conditions so that it is optimal and any other optimal policy meets those conditions. Taking into account that the LT debt bail-in rules impose the lower bound $h_{1} \geq h_{1}^{*}=H_{\text {res }}$ we easily deduce from (64) that any other optimal policy $\left(\alpha^{\prime}, h_{1}^{\prime}, T^{\prime}\right)$ must have $h_{1}^{\prime}=h_{1}^{*}, T^{\prime}=T^{*}$, and the proposition is satisfied.

Suppose the authority does not have bail-in powers so that intervention policies are described by the pair $(\alpha, T)$. We are going to show that there exist values of the bank's balance sheet parameters such that not inducing new lending by the bank strictly reduces the cost of the bank for the authority relative to any policy that induces it.

Consider the limit case with $h_{0}=1-\gamma, d_{0}=0, x=1$, and $y>0$ such that $\left(E\left[B_{s}\right]-1\right) y<$ $1-\gamma-E\left[Q_{s}\right]$. Suppose the authority sets a policy with $T=0$. Then, since the bank has no deposits, the cost for the authority of such policy is zero. We have from (64) that if a policy $(\alpha, T)$ induces full lending then it must necessarily satisfy $T>0$ and thus has a strictly higher cost than any policy with no transfers.

\section{B.7 Interventions without public transfers}

The next proposition states formally the results discussed in Section 6.4: 
Proposition 8 (The cost of prohibiting public transfers) Whenever the optimal intervention of the class $(\alpha, T)$ features $T^{*}>0$, then optimal interventions of the class $(\alpha, T=0)$ lead to resolution. Moreover, the the overall expected cost for the authority in the optimal interventions of the class $(\alpha, T=0)$ are increased by $\left(E\left[B_{s}\right]-1\right) y$ relative to those under the optimal intervention of the class $(\alpha, T)$.

Proof Consider a constrained authority that must set $T=0$. Its objective would then reduce to minimize the cost of the bank to the DGS, $G$, and its only tool would be the fractional NPL disposal requirement, $\alpha$. Denote $\left(\alpha^{*}, T^{*}\right)$ the minimal (unconstrained) optimal policy, which is described in Proposition 1. Suppose that $T^{*}>0$. Then Lemma 1 implies that the net continuation value of the bank to its owners under $\left(\alpha^{*}, T^{*}\right)$ satisfies $\Pi^{*}=0$.

Let $\alpha$ be an intervention policy and denote $\Pi(\alpha)$ bank owners' net value if the bank is compliant with it, and $G(\alpha)$ the cost of the bank to the DGS under the optimal decision of the bank under such policy.

Suppose that $\alpha \geq \alpha^{*}$. We have that

$$
\Pi(\alpha)=\Pi^{*}-T^{*}<0,
$$

where we have used (12) and the fact that after disposing of a fraction $\alpha^{*}$ (or $\alpha \geq \alpha^{*}$ ) of its NPLs the bank finds optimal to undertake its new lending in full and, conditional on that, it is solvent in the two states. But then under $\alpha$ the bank finds optimal not to be compliant, implying

$$
G(\alpha)=1-\gamma-E\left[Q_{s}\right] x-E\left[B_{s}\right](1-x),
$$

which does not depend on the exact value of $\alpha \geq \alpha^{*}$ and we can hereafter refer to as $G\left(\alpha^{*}\right)$. Using (18) and (65), we deduce that

$$
G\left(\alpha^{*}\right)=\left(E\left[B_{s}\right]-1\right) y+T^{*}>0 .
$$

Suppose that $\alpha<\alpha^{*}$. If the bank finds optimal to opt for resolution then its cost to the DGS is given by (66) and hence equals $G\left(\alpha^{*}\right)>0$. If instead the bank finds optimal to be compliant, it will not undertake any new lending, which means

$$
\Pi(\alpha)=E\left[Q_{s}\right] x+E\left[B_{s}\right](1-x)-(1-\gamma)+G(\alpha) \geq 0,
$$

or, equivalently,

$$
G(\alpha) \geq 1-\gamma-E\left[Q_{s}\right] x-E\left[B_{s}\right](1-x)=G\left(\alpha^{*}\right)
$$

which means that setting $\alpha \geq \alpha^{*}$ and pushing the bank into resolution is less costly. This concludes the proof that any policy that leads to resolution is optimal for the constrained authority.

Moreover, taking into account that the cost for the DGS under any optimal constrained policy is equal to $G\left(\alpha^{*}\right)$, equation (67) implies that the cost of the bank to the DGS under the constrained optimal policy exceeds the transfer $T^{*}$ associated with the minimal unconstrained optimal policy. 


\section{The high $\mu$ case}

Here we characterize the optimal intervention policies when Assumption 3 is not satisfied and show that the main results in Proposition 1 still hold. The main difference is that in this case the debt overhang problem is never strong enough so as to discourage the bank owners from undertaking the new lending. As a result, NPL disposals are not necessary to induce full lending. Yet, they are still useful as they reduce the expected cost of the bank to the DGS (Lemma 2).

Suppose that $\mu \geq \frac{\gamma}{B_{H}-1+\gamma}$. We briefly reproduce the arguments and present analogous results to those in Sections 5.2 and 5.3 in the baseline model.

Optimal investment by a compliant bank By definition of $\mu$, we have from (13) that $\frac{\partial \Pi(\alpha, T, I \mid x)}{\partial I}>0$ for all $\alpha, T, I$, and $x$. As a result a compliant bank always finds optimal to undertake its new lending in full.

Optimal intervention and the need for public transfers Taking into account that undertaking its new lending is always optimal for a compliant bank, for a given policy $(\alpha, T)$, the bank finds optimal to be compliant if $\Pi(\alpha, T, y \mid x) \geq 0$ or, equivalently,

$$
E\left[Q_{s}\right] x+E\left[B_{s}\right](1-x)-(1-\gamma)+T+\left(E\left[B_{s}\right]-1\right) y+G(\alpha, y \mid x) \geq 0,
$$

where the last term is positive if and only if $\alpha<\alpha_{\text {solv }}(y, x)$. Moreover, Lemma 1 implies the optimality of any policy $(\alpha, T)$ for which either $C=T+G(\alpha, y \mid x)=0$ or inequality (68) is binding. Recall also that a minimal optimal policy is an optimal policy with minimal $T$ and, conditional on that, with minimal $\alpha$.

We have the following result that extends Proposition 1 to the high $\mu$ case:

Proposition 9 (Optimal minimal intervention under high $\mu$ ) Any optimal intervention by the authority satisfies the sufficient condition in Lemma 1. In particular, the authority's minimal optimal intervention $\left(\alpha^{*}, T^{*}\right)$ avoids resolution, leads the bank to undertake its new lending in full, and has an expected cost to the authority given by

$$
C^{*}=\left(1-\gamma-E\left[Q_{s}\right] x-E\left[B_{s}\right](1-x)-\left(E\left[B_{s}\right]-1\right) y\right)^{+} .
$$

Moreover, $C^{*}$ is increasing in $x$ and decreasing in $y$, and strictly so when $C^{*}>0$. In addition,

$$
\begin{cases}\alpha^{*}=\alpha_{\text {solv }}(y, x), T^{*}=0, & \text { if }\left(E\left[B_{s}\right]-1\right) y \geq(1-\gamma)-E\left[Q_{s}\right] x+E\left[B_{s}\right](1-x), \\ \alpha^{*}=0, T^{*}>0, & \text { if }\left(E\left[B_{s}\right]-1\right) y+G(0, y \mid x)<(1-\gamma)-E\left[Q_{s}\right] x+E\left[B_{s}\right](1-x), \\ \alpha^{*}<\alpha_{\text {solv }}(y, x), T^{*}=0, & \text { if }\left(E\left[B_{s}\right]-1\right) y<(1-\gamma)-E\left[Q_{s}\right] x+E\left[B_{s}\right](1-x) \leq\left(E\left[B_{s}\right]-1\right) y+G(0, y \mid x) .\end{cases}
$$

Proof We proceed in a sequence of steps. 
i) Any optimal intervention satisfies the sufficient condition in Lemma 1. Consider the policy $\left(1, T^{\prime}\right)$ where $T^{\prime}$ satisfies

$$
T^{\prime}=\left(1-\gamma-E\left[Q_{s}\right] x-E\left[B_{s}\right](1-x)-\left(E\left[B_{s}\right]-1\right) y\right)^{+} .
$$

Then one can prove that $\left(1, T^{\prime}\right)$ satisfies the conditions in Lemma 1 and thus the lemma implies that $\left(1, T^{\prime}\right)$ is optimal and any optimal policy satisfies those conditions.

Let $\left(\alpha^{*}, T^{*}\right)$ be the minimal optimal intervention policy and $\Pi^{*}, C^{*}$, and $T^{*}$ the induced values for the variables $\Pi, C$, and $T$.

ii) $C^{*}$ satisfies (69). It suffices to notice that $\left(1, T^{\prime}\right)$ is an optimal policy under which the DGS does not incur any cost and that, by definition, the overall cost to the authority is the same for all optimal policies

iii) $\alpha^{*}=\alpha_{\text {solv }}(y, x)$ if $\left(E\left[B_{s}\right]-1\right) y \geq(1-\gamma)-E\left[Q_{s}\right] x+E\left[B_{s}\right](1-x)$. Suppose the inequality is satisfied. Then (69) implies that $C^{*}=0$ and it has to be the case that $T^{*}=0$ and the bank is solvent in the two states, which in turn implies that $\alpha^{*} \geq \alpha_{\text {solv }}(y, x)$. Since $\left(\alpha^{*}, T^{*}\right)$ is minimal, we must have $\alpha^{*}=\alpha_{\text {solv }}(y, x)$.

iv) $\alpha^{*}=0$ and $T^{*}>0$ if $\left(E\left[B_{s}\right]-1\right) y+G(0, y \mid x)<(1-\gamma)-E\left[Q_{s}\right] x+E\left[B_{s}\right](1-x)$. Suppose the inequality is satisfied. Then we have from (69) that $C^{*}>G(0, y \mid x) \geq 0$. Let $\alpha^{*}=0$ and $T^{*}=C^{*}-G(0, y \mid x)>0$, then $\left(\alpha^{*}, T^{*}\right)$ satisfies the conditions in Lemma 1 and is thus optimal. In addition, any other optimal policy $(\widetilde{\alpha}, \widetilde{T})$ must have $\widetilde{T}=C^{*}-G(\widetilde{\alpha}, y \mid x)$ and using that $G(\alpha, y \mid x)$ is decreasing in $\alpha$ (Lemma 2) we conclude that $\left(\alpha^{*}, T^{*}\right)$ is the minimal optimal policy.

v) $\alpha^{*}<\alpha_{\text {solv }}(y, x)$ and $T^{*}=0$ if $\left(E\left[B_{s}\right]-1\right) y<(1-\gamma)-E\left[Q_{s}\right] x+E\left[B_{s}\right](1-x) \leq$ $\left(E\left[B_{s}\right]-1\right) y+G(0, y \mid x)$. Suppose the inequality is satisfied. Then we have from (69) that $C^{*}>0$ and that $G(0, y \mid x)>0$, which implies $\alpha_{\text {solv }}(y, x)>0$. Using that $G(\alpha, y \mid x)$ is decreasing in $\alpha$, strictly so when $G(\alpha, y \mid x)>0$ and $G(1, y \mid x)=0$, we have that there exists a unique solution in $\alpha$ to the equation

$$
(1-\gamma)-E\left[Q_{s}\right] x+E\left[B_{s}\right](1-x)=\left(E\left[B_{s}\right]-1\right) y+G(\alpha, y \mid x) .
$$

Let $\alpha^{*}$ be such solution and $T^{*}=0$, then $\left(\alpha^{*}, T^{*}\right)$ satisfies the conditions in Lemma 1 and is thus optimal. The minimality of $\left(\alpha^{*}, T^{*}\right)$ is proven as in iv) taking into account that $G\left(\alpha^{*}, y \mid x\right)>0$ and the monotonicity of $G(\alpha, y \mid x)$ in $\alpha$. Finally, we have that $\alpha^{*}<\alpha_{\text {solv }}(y, x)$ since $G\left(\alpha^{*}, y \mid x\right)>0$. 


\section{RECENTLY PUBLISHED “TEMI” (*)}

N.1201 - Contagion in the CoCos market? A case study of two stress events, by Pierluigi Bologna, Arianna Miglietta and Anatoli Segura (November 2018).

N. 1202 - Is ECB monetary policy more powerful during expansions?, by Martina Cecioni (December 2018).

N. 1203 - Firms' inflation expectations and investment plans, by Adriana Grasso and Tiziano Ropele (December 2018).

N. 1204 - Recent trends in economic activity and TFP in Italy with a focus on embodied technical progress, by Alessandro Mistretta and Francesco Zollino (December 2018).

N.1205 - Benefits of Gradualism or Costs of Inaction? Monetary Policy in Times of Uncertainty, by Giuseppe Ferrero, Mario Pietrunti and Andrea Tiseno (February 2019).

N.1206 - Machine learning in the service of policy targeting: the case of public credit guarantees, by Monica Andini, Michela Boldrini, Emanuele Ciani, Guido de Blasio, Alessio D'Ignazio and Andrea Paladini (February 2019).

N. 1207 - Do the ECB's monetary policies benefit Emerging Market Economies? A GVAR analysis on the crisis and post-crisis period, by Andrea Colabella (February 2019).

N. 1208 - The Economic Effects of Big Events: Evidence from the Great Jubilee 2000 in Rome, by Raffaello Bronzini, Sauro Mocetti and Matteo Mongardini (February 2019).

N. 1209 - The added value of more accurate predictions for school rankings, by Fritz Schiltz, Paolo Sestito, Tommaso Agasisti and Kristof De Witte (February 2019).

N.1210 - Identification and estimation of triangular models with a binary treatment, by Santiago Pereda Fernández (March 2019).

N. 1211 - U.S. shale producers: a case of dynamic risk management, by Fabrizio Ferriani and Giovanni Veronese (March 2019).

N.1212 - Bank resolution and public backstop in an asymmetric banking union, by Anatoli Segura Velez (March 2019).

N. 1213 - A regression discontinuity design for categorical ordered running variables with an application to central bank purchases of corporate bonds, by Fan Li, Andrea Mercatanti, Taneli Mäkinen and Andrea Silvestrini (March 2019).

N.1214 - Anything new in town? The local effects of urban regeneration policies in Italy, by Giuseppe Albanese, Emanuele Ciani and Guido de Blasio (April 2019).

N. 1215 - Risk premium in the era of shale oil, by Fabrizio Ferriani, Filippo Natoli, Giovanni Veronese and Federica Zeni (April 2019).

N.1216 - Safety traps, liquidity and information-sensitive assets, by Michele Loberto (April 2019).

N. 1217 - Does trust among banks matter for bilateral trade? Evidence from shocks in the interbank market, by Silvia Del Prete and Stefano Federico (April 2019).

N.1218 - Monetary policy, firms' inflation expectations and prices: causal evidence from firm-level data, by Marco Bottone and Alfonso Rosolia (April 2019).

N.1219 - Inflation expectations and firms' decisions: new causal evidence, by Olivier Coibion, Yuriy Gorodnichenko and Tiziano Ropele (April 2019).

N. 1220 - Credit risk-taking and maturity mismatch: the role of the yield curve, by Giuseppe Ferrero, Andrea Nobili and Gabriele Sene (April 2019).

(*) Requests for copies should be sent to:

Banca d'Italia - Servizio Studi di struttura economica e finanziaria - Divisione Biblioteca e Archivio storico - Via Nazionale, 91 - 00184 Rome - (fax 003906 47922059). They are available on the Internet www.bancaditalia.it. 
Aaberge, R., F. Bourguignon, A. Brandolini, F. Ferreira, J. Gornick, J. Hills, M. Jäntti, S. Jenkins, J. Micklewright, E. Marlier, B. Nolan, T. Piketty, W. Radermacher, T. Smeeding, N. Stern, J. Stiglitz, H. Sutherland, Tony Atkinson and his legacy, Review of Income and Wealth, v. 63, 3, pp. 411-444, WP 1138 (September 2017).

AcCetturo A., M. Bugamelli and A. LAmorgese, Law enforcement and political participation: Italy 1861-65, Journal of Economic Behavior \& Organization, v. 140, pp. 224-245, WP 1124 (July 2017).

AdAmopoulou A. and G.M. TANZI, Academic dropout and the great recession, Journal of Human Capital, V. 11, 1, pp. 35-71, WP 970 (October 2014).

Albertazzi U., M. BotTero and G. SENE, Information externalities in the credit market and the spell of credit rationing, Journal of Financial Intermediation, v. 30, pp. 61-70, WP 980 (November 2014).

AlESSANDRI P. and H. MUMTAZ, Financial indicators and density forecasts for US output and inflation, Review of Economic Dynamics, v. 24, pp. 66-78, WP 977 (November 2014).

BARbieri G., C. Rossetti and P. SESTITO, Teacher motivation and student learning, Politica economica/Journal of Economic Policy, v. 33, 1, pp.59-72, WP 761 (June 2010).

Bentivogli C. and M. LitTERIO, Foreign ownership and performance: evidence from a panel of Italian firms, International Journal of the Economics of Business, v. 24, 3, pp. 251-273, WP 1085 (October 2016).

BRONZINI R. and A. D'IGNAZIO, Bank internationalisation and firm exports: evidence from matched firmbank data, Review of International Economics, v. 25, 3, pp. 476-499 WP 1055 (March 2016).

BRUChE M. and A. SEgurA, Debt maturity and the liquidity of secondary debt markets, Journal of Financial Economics, v. 124, 3, pp. 599-613, WP 1049 (January 2016).

Burlon L., Public expenditure distribution, voting, and growth, Journal of Public Economic Theory,, v. 19, 4, pp. 789-810, WP 961 (April 2014).

Burlon L., A. Gerali, A. Notarpietro and M. PisAni, Macroeconomic effectiveness of non-standard monetary policy and early exit. a model-based evaluation, International Finance, v. 20, 2, pp.155173, WP 1074 (July 2016).

BusEtTi F., Quantile aggregation of density forecasts, Oxford Bulletin of Economics and Statistics, v. 79, 4, pp. 495-512, WP 979 (November 2014).

CESARONI T. and S. IEZZI, The predictive content of business survey indicators: evidence from SIGE, Journal of Business Cycle Research, v.13, 1, pp 75-104, WP 1031 (October 2015).

CONTI P., D. MARELLA and A. NERI, Statistical matching and uncertainty analysis in combining household income and expenditure data, Statistical Methods \& Applications, v. 26, 3, pp 485-505, WP 1018 (July 2015).

D’AMURI F., Monitoring and disincentives in containing paid sick leave, Labour Economics, v. 49, pp. 7483, WP 787 (January 2011).

D'AMURI F. and J. MARCUCCI, The predictive power of google searches in forecasting unemployment, International Journal of Forecasting, v. 33, 4, pp. 801-816, WP 891 (November 2012).

DE BLASIO G. and S. POY, The impact of local minimum wages on employment: evidence from Italy in the 1950s, Journal of Regional Science, v. 57, 1, pp. 48-74, WP 953 (March 2014).

Del Giovane P., A. NoBiLi and F. M. SignORETTI, Assessing the sources of credit supply tightening: was the sovereign debt crisis different from Lehman?, International Journal of Central Banking, v. 13, 2, pp. 197-234, WP 942 (November 2013).

Del Prete S., M. PAGNini, P. Rossi and V. VACCA, Lending organization and credit supply during the 2008-2009 crisis, Economic Notes, v. 46, 2, pp. 207-236, WP 1108 (April 2017).

Delle Monache D. and I. Petrella, Adaptive models and heavy tails with an application to inflation forecasting, International Journal of Forecasting, v. 33, 2, pp. 482-501, WP 1052 (March 2016).

FEDERICO S. and E. TOSTI, Exporters and importers of services: firm-level evidence on Italy, The World Economy, v. 40, 10, pp. 2078-2096, WP 877 (September 2012).

Giacomelli S. and C. MENON, Does weak contract enforcement affect firm size? Evidence from the neighbour's court, Journal of Economic Geography, v. 17, 6, pp. 1251-1282, WP 898 (January 2013).

Loberto M. and C. Perricone, Does trend inflation make a difference?, Economic Modelling, v. 61, pp. 351-375, WP 1033 (October 2015). 
MANCINI A.L., C. MonfARdini and S. PASQUA, Is a good example the best sermon? Children's imitation of parental reading, Review of Economics of the Household, v. 15, 3, pp 965-993, D No. 958 (April 2014).

MEEKS R., B. NELSON and P. AlessANDRI, Shadow banks and macroeconomic instability, Journal of Money, Credit and Banking, v. 49, 7, pp. 1483-1516, WP 939 (November 2013).

MiCUCCI G. and P. Rossi, Debt restructuring and the role of banks' organizational structure and lending technologies, Journal of Financial Services Research, v. 51, 3, pp 339-361, WP 763 (June 2010).

Mocetti S., M. PAGNini and E. SETTE, Information technology and banking organization, Journal of Journal of Financial Services Research, v. 51, pp. 313-338, WP 752 (March 2010).

MocetTi S. and E. ViVIANO, Looking behind mortgage delinquencies, Journal of Banking \& Finance, v. 75, pp. 53-63, WP 999 (January 2015).

NoBili A. and F. Zollino, A structural model for the housing and credit market in Italy, Journal of Housing Economics, v. 36, pp. 73-87, WP 887 (October 2012).

PALAZzO F., Search costs and the severity of adverse selection, Research in Economics, v. 71, 1, pp. 171197, WP 1073 (July 2016).

Patacchini E. and E. Rainone, Social ties and the demand for financial services, Journal of Financial Services Research, v. 52, 1-2, pp 35-88, WP 1115 (June 2017).

PATACCHINI E., E. RAINONE and Y. ZENOU, Heterogeneous peer effects in education, Journal of Economic Behavior \& Organization, v. 134, pp. 190-227, WP 1048 (January 2016).

SBrana G., A. Silvestrini and F. VenditTI, Short-term inflation forecasting: the M.E.T.A. approach, International Journal of Forecasting, v. 33, 4, pp. 1065-1081, WP 1016 (June 2015).

SEgurA A. and J. SuAREZ, How excessive is banks' maturity transformation?, Review of Financial Studies, v. 30, 10, pp. 3538-3580, WP 1065 (April 2016).

VACCA V., An unexpected crisis? Looking at pricing effectiveness of heterogeneous banks, Economic Notes, v. 46, 2, pp. 171-206, WP 814 (July 2011).

Vergara CAFFAReli F., One-way flow networks with decreasing returns to linking, Dynamic Games and Applications, v. 7, 2, pp. 323-345, WP 734 (November 2009).

ZAGHINI A., A Tale of fragmentation: corporate funding in the euro-area bond market, International Review of Financial Analysis, v. 49, pp. 59-68, WP 1104 (February 2017).

Accetturo A., v. Di Giacinto, G. Micucci and M. Pagnini, Geography, productivity and trade: does selection explain why some locations are more productive than others?, Journal of Regional Science, v. 58, 5, pp. 949-979, WP 910 (April 2013).

AdAmopoulou A. and E. KAYA, Young adults living with their parents and the influence of peers, Oxford Bulletin of Economics and Statistics,v. 80, pp. 689-713, WP 1038 (November 2015).

ANDini M., E. Ciani, G. DE Blasio, A. D'Ignazio and V. Silvestrini, Targeting with machine learning: an application to a tax rebate program in Italy, Journal of Economic Behavior \& Organization, v. 156, pp. 86-102, WP 1158 (December 2017).

BARONE G., G. DE BLASIO and S. MOCETTI, The real effects of credit crunch in the great recession: evidence from Italian provinces, Regional Science and Urban Economics, v. 70, pp. 352-59, WP 1057 (March 2016).

Belotti F. and G. IlARDI Consistent inference in fixed-effects stochastic frontier models, Journal of Econometrics, v. 202, 2, pp. 161-177, WP 1147 (October 2017).

Berton F., S. Mocetti, A. Presbitero and M. Richiardi, Banks, firms, and jobs, Review of Financial Studies, v.31, 6, pp. 2113-2156, WP 1097 (February 2017).

Bofondi M., L. CARPInElli and E. SETTE, Credit supply during a sovereign debt crisis, Journal of the European Economic Association, v.16, 3, pp. 696-729, WP 909 (April 2013).

BokAn N., A. Gerali, S. Gomes, P. JACQUINOT and M. PISANI, EAGLE-FLI: a macroeconomic model of banking and financial interdependence in the euro area, Economic Modelling, v. 69, C, pp. 249280, WP 1064 (April 2016). 
BRILli Y. and M. TONELlo, Does increasing compulsory education reduce or displace adolescent crime? New evidence from administrative and victimization data, CESifo Economic Studies, v. 64, 1, pp. 15-4, WP 1008 (April 2015).

BUONO I. and S. FORMAI The heterogeneous response of domestic sales and exports to bank credit shocks, Journal of International Economics, v. 113, pp. 55-73, WP 1066 (March 2018).

Burlon L., A. GERAli, A. NotARPIETRO and M. PisAnI, Non-standard monetary policy, asset prices and macroprudential policy in a monetary union, Journal of International Money and Finance, v. 88, pp. 25-53, WP 1089 (October 2016).

CARTA F. and M. DE PHLIPPIS, You've Come a long way, baby. Husbands' commuting time and family labour supply, Regional Science and Urban Economics, v. 69, pp. 25-37, WP 1003 (March 2015).

CARTA F. and L. RIzZICA, Early kindergarten, maternal labor supply and children's outcomes: evidence from Italy, Journal of Public Economics, v. 158, pp. 79-102, WP 1030 (October 2015).

Casiraghi M., E. Gaiotti, L. Rodano and A. Secchi, A "Reverse Robin Hood”? The distributional implications of non-standard monetary policy for Italian households, Journal of International Money and Finance, v. 85, pp. 215-235, WP 1077 (July 2016).

CECChetti S., F. NATOLI and L. SigAlotTI, Tail co-movement in inflation expectations as an indicator of anchoring, International Journal of Central Banking, v. 14, 1, pp. 35-71, WP 1025 (July 2015).

CIANI E. and C. DEIANA, No Free lunch, buddy: housing transfers and informal care later in life, Review of Economics of the Household, v.16, 4, pp. 971-1001, WP 1117 (June 2017).

Cipriani M., A. Guarino, G. Guazzarotti, F. TAgliati and S. Fisher, Informational contagion in the laboratory, Review of Finance, v. 22, 3, pp. 877-904, WP 1063 (April 2016).

De Blasio G, S. De Mitri, S. D’Ignazio, P. Finaldi Russo and L. Stoppani, Public guarantees to SME borrowing. A RDD evaluation, Journal of Banking \& Finance, v. 96, pp. 73-86, WP 1111 (April 2017).

Gerali A., A. LocARno, A. NotArPIETRO and M. PISANI, The sovereign crisis and Italy's potential output, Journal of Policy Modeling, v. 40, 2, pp. 418-433, WP 1010 (June 2015).

LIBERATI D., An estimated DSGE model with search and matching frictions in the credit market, International Journal of Monetary Economics and Finance (IJMEF), v. 11, 6, pp. 567-617, WP 986 (November 2014).

Linarello A., Direct and indirect effects of trade liberalization: evidence from Chile, Journal of Development Economics, v. 134, pp. 160-175, WP 994 (December 2014).

NuCCI F. and M. RIGgI, Labor force participation, wage rigidities, and inflation, Journal of Macroeconomics, v. 55, 3 pp. 274-292, WP 1054 (March 2016).

RIGON M. and F. ZANETTI, Optimal monetary policy and fiscal policy interaction in a non_ricardian economy, International Journal of Central Banking, v. 14 3, pp. 389-436, WP 1155 (December 2017).

SEGURA A., Why did sponsor banks rescue their SIVs?, Review of Finance, v. 22, 2, pp. 661-697, WP 1100 (February 2017).

ARnAudo D., G. MiCUCCI, M. RIGON and P. Rossi, Should I stay or should I go? Firms' mobility across banks in the aftermath of the financial crisis, Italian Economic Journal / Rivista italiana degli economisti, v. 5, 1, pp. 17-37, WP 1086 (October 2016).

CIANI E., F. DAVID and G. DE BLASIO, Local responses to labor demand shocks: a re-assessment of the case of Italy, Regional Science and Urban Economics, v. 75, pp. 1-21, WP 1112 (April 2017).

CIANI E. and P. FISHER, Dif-in-dif estimators of multiplicative treatment effects, Journal of Econometric Methods, v. 8. 1, pp. 1-10, WP 985 (November 2014).

Chiades P., L. Greco, V. Mengotto, L. Moretti and P. Valbonesi, Fiscal consolidation by intergovernmental transfers cuts? The unpleasant effect on expenditure arrears, Economic Modelling, v. 77, pp. 266-275, WP 985 (July 2016). 
Giordano C., M. MARINUCCI and A. SiLveSTRINI, The macro determinants of firms' and households' investment: evidence from Italy, Economic Modelling, v. 78, pp. 118-133, WP 1167 (March 2018).

MONTEFORTE L. and V. RAPONI, Short-term forecasts of economic activity: are fortnightly factors useful?, Journal of Forecasting, v. 38, 3, pp. 207-221, WP 1177 (June 2018).

RigGi M., Capital destruction, jobless recoveries, and the discipline device role of unemployment, Macroeconomic Dynamics, v. 23, 2, pp. 590-624, WP 871 (July 2012).

\section{FORTHCOMING}

Albanese G., G. DE Blasio and P. Sestito, Trust, risk and time preferences: evidence from survey data, International Review of Economics, WP 911 (April 2013).

Aprigliano V., G. ARDIZZI and L. MONTEFORTE, Using the payment system data to forecast the economic activity, International Journal of Central Banking, WP 1098 (February 2017).

ARDUINI T., E. PATACCHINI and E. RAINONE, Treatment effects with heterogeneous externalities, Journal of Business \& Economic Statistics, WP 974 (October 2014).

BElotti F. and G. ILARDI, Consistent inference in fixed-effects stochastic frontier models, Journal of Econometrics, WP 1147 (October 2017).

BusetTi F. and M. CAIVANO, Low frequency drivers of the real interest rate: empirical evidence for advanced economies, International Finance, WP 1132 (September 2017).

Cappelletti G., G. Guazzarotti and P. Tommasino, Tax deferral and mutual fund inflows: evidence from a quasi-natural experiment, Fiscal Studies, WP 938 (November 2013).

CIANI E. and G. DE BLASIO, European structural funds during the crisis: evidence from Southern Italy, IZA Journal of Labor Policy, WP 1029 (October 2015).

COletta M., R. De Bonis and S. PIERMATteI, Household debt in OECD countries: the role of supply-side and demand-side factors, Social Indicators Research, WP 989 (November 2014).

CORSELlO F. and V. NISPI LANDI, Labor market and financial shocks: a time-varying analysis, Journal of Money, Credit and Banking, WP 1179 (June 2018).

Cova P., P. PAGANO and M. PISANI, Domestic and international macroeconomic effects of the Eurosystem Expanded Asset Purchase Programme, IMF Economic Review, WP 1036 (October 2015).

D’AMURI F., Monitoring and disincentives in containing paid sick leave, Labour Economics, WP 787 (January 2011).

D'Ignazio A. and C. MENOn, The causal effect of credit Guarantees for SMEs: evidence from Italy, Scandinavian Journal of Economics, WP 900 (February 2013).

ERCOLANi V. and J. VAlle E AzEVEDO, How can the government spending multiplier be small at the zero lower bound?, Macroeconomic Dynamics, WP 1174 (April 2018).

FEDERICO S. and E. TOSTI, Exporters and importers of services: firm-level evidence on Italy, The World Economy, WP 877 (September 2012).

GERAli A. and S. NeRI, Natural rates across the Atlantic, Journal of Macroeconomics, WP 1140 (September 2017).

Giacomelli S. and C. Menon, Does weak contract enforcement affect firm size? Evidence from the neighbour's court, Journal of Economic Geography, WP 898 (January 2013).

NAtoli F. and L. SigalotTI, Tail co-movement in inflation expectations as an indicator of anchoring, International Journal of Central Banking, WP 1025 (July 2015).

RAINONE E., The network nature of otc interest rates, Journal of Financial Markets, WP 1022 (July 2015).

RIZZICA L., Raising aspirations and higher education. evidence from the UK's widening participation policy, Journal of Labor Economics, WP 1188 (September 2018).

SEGURA A., Why did sponsor banks rescue their SIVs?, Review of Finance, WP 1100 (February 2017). 